\title{
Autologous Muscular Treatment Options for Endstage Heart Failure - A Critical Appraisal of the Dynamic Cardiomyoplasty (DCMP) vs. a New Concept of a Closed- Loop Controlled DCMP (CLC-DCMP)
}

\author{
Norbert W. Guldner, Peter Klapproth and \\ Hans-H. Sievers \\ Additional information is available at the end of the chapter \\ http://dx.doi.org/10.5772/55900
}

\section{Introduction}

Dynamic cardiomyoplasty (DCMP) aims at improving cardiac function in cases of severe heart failure by wrapping the latissimus dorsi (LD) muscle, (usually left LD) around the ventricles and stimulating it electrically, synchronously to the ventricular function (Figure 1, Figure 2). It is a surgical treatment option mostly for pharmacologically untreatable heart failure. The first successful clinical application was performed in 1985 (Broussais Hospital, Paris, [1]). Since then, more than 1.000 surgeries have been performed worldwide [2]. The clinical results of the DCMP however did not live up to the expectations due to the loss of muscle strength [3][4] and muscle damage [5][6].

In DCMP, a special kind of tissue engineering is applied using an electric stimulation on autologous skeletal muscles (electrical muscular tissue engineering). The fiber type changes from the fatiguing type IIa to the fatigue resistant type I [7], [8]. Type IIx fibers disappear. The gene expression for myosin heavy chains IIa (MHCII) is changed into heavy chains I (MHCI) [3]. Intramuscular collaterals are opened [9], [10] and enhanced and capillary density is increased [11].

A critical analysis of more than 20 years and more than 1.000 clinical cases should demonstrate it's clinical impact [1], [2], [4-6], [12-145]. Clinical efficacy concerning survival, clinical outcome indicated by NYHA- class, ejection fraction of the left heart ventricle (EF) was evaluated by the use of more than 100 relevant reports. A comparison of the DCMP therapy 


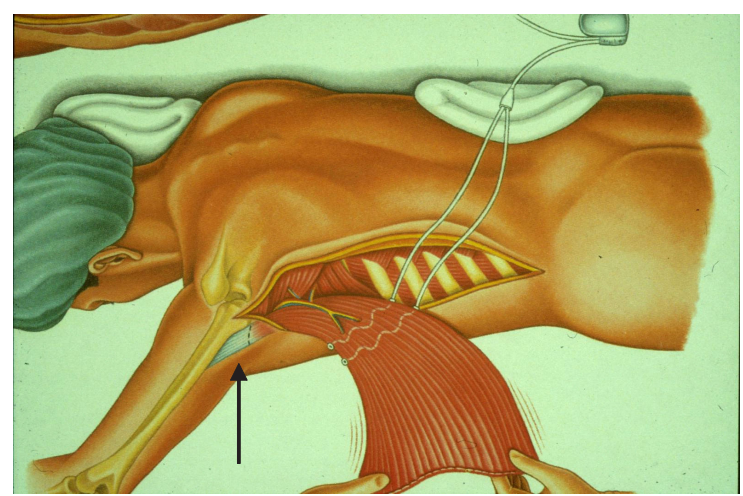

Figure 1. Latissimus dorsi muscle (LDM) is dissected free from the left thoracic wall before placing it into the thoracic cavity via a window of the thoracic wall after a partial resection of the second rib. Artery, vein and nervus thoracodorsalis remain untouched. LDM's tendon is cut (arrow) before it's re-fixation to the thoracic wall. Two stimulation electrodes are placed wavelike around the branches of nervus thoracodorsalis at a distance of $6 \mathrm{~cm}$.

to other treatment options for end-stage heart failure is performed in this report. And last but not least new experimental insights concerning the DCMP procedure should be demonstrated. This experience from clinical application over more than 20 years and new experimental data about dynamic cardiomyoplasty procedures should become compared and discussed. From these insights, conclusions should be drawn to improve clinically results from DCMP which are needed urgently for a more effective treatment of pharmacologically non-treatable heart failure.

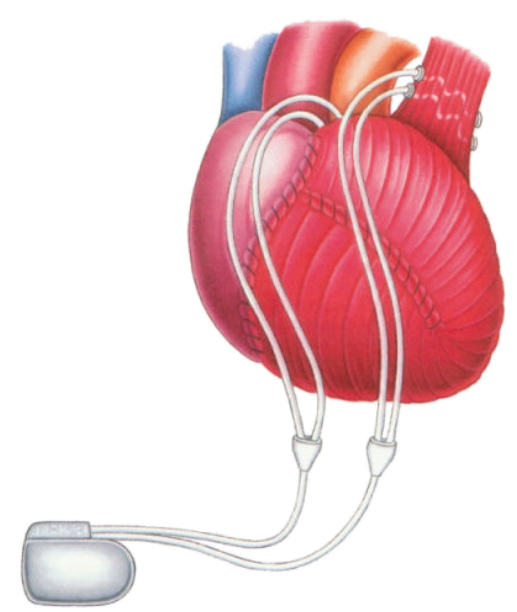

Figure 2. When latissimus dorsi muscle (LDM) has been transferred intra-thoracally it is wrapped around the heart and stimulated electrically by a myostimulator via two muscular electrodes near the branches of the thoraco-dorsal nerve. Stimulation bursts are synchronized with the heart action via additional epicardial sensing electrodes. 


\section{Clinical efficacy of DCMP}

\subsection{Survival}

An analysis of survival curves of different investigators for DCMP-procedures shown in figure 3 may give insights in factors determining the best survival rate.

\subsubsection{Survival rate and NYHA - Class}

Observing and comparing the survival curves in figure 3 demonstrates, that a pre-operative NYHA class III has a better long term survival than NYHA class IV. In the upper half of the diagram with the higher survival, NYHA III is predominantly present while in the lower half mostly appears NYHA IV.

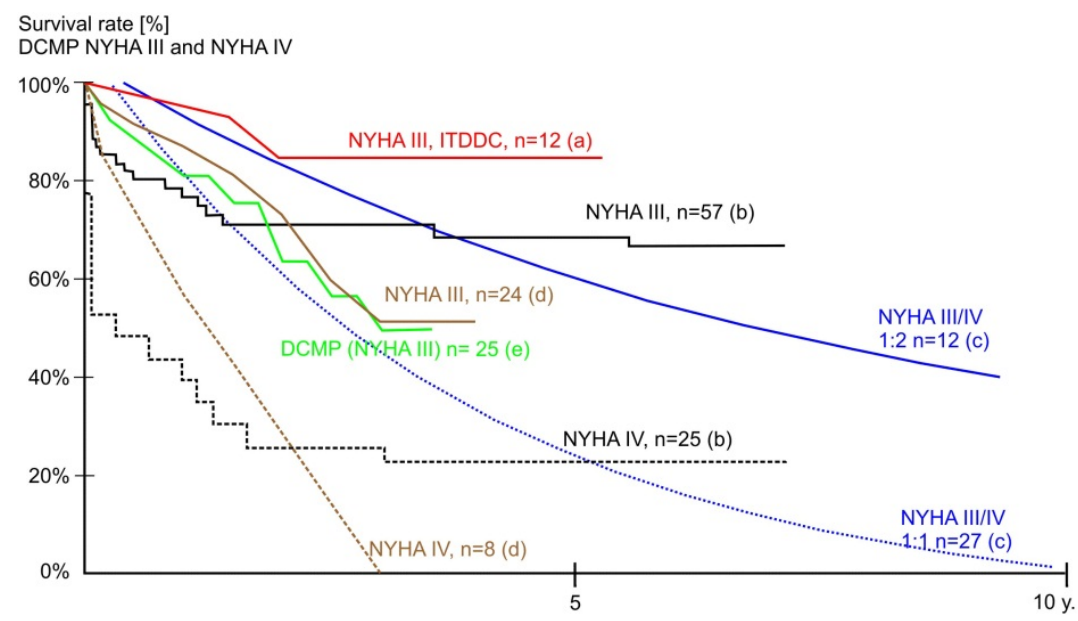

Figure 3. Survival rates of patients with a DCMP published by different authors (a) Rigatelle et al, 2002 (ITDDC = Italien Demand Dynamic Cardiomyoplasty) [118] (b) Chachques et al. 1997 [37] (c) Benicio et al. 2003, [20] (d) Bocchi et al. 1994, [25] (e) Bocchi et al. 1996 [23]

To demonstrate the influence of the pre-operative NYHA class, results of the "French DCMP Experience" from the year 1997 are selected from figure 3 and documented in figure 4 separately. The survival rate of class NYHA III patients at 5 years after DCMP was $68 \%$ compared to NYHA IV with $23 \%$ (Chachques JC, 1997) [37]. Another group reports (figure 3 (d)) about no survivor of pre-operative NYHA IV patients 3 years after the DCMP procedure [25].

\subsubsection{Survival rate and stimulation pattern}

A re-evaluation of long-term outcomes of dynamic cardiomyoplasties from the Sao Paulo Group Brazil [20] in 43 patients with dilated cardiomyopathies showed impressive results 


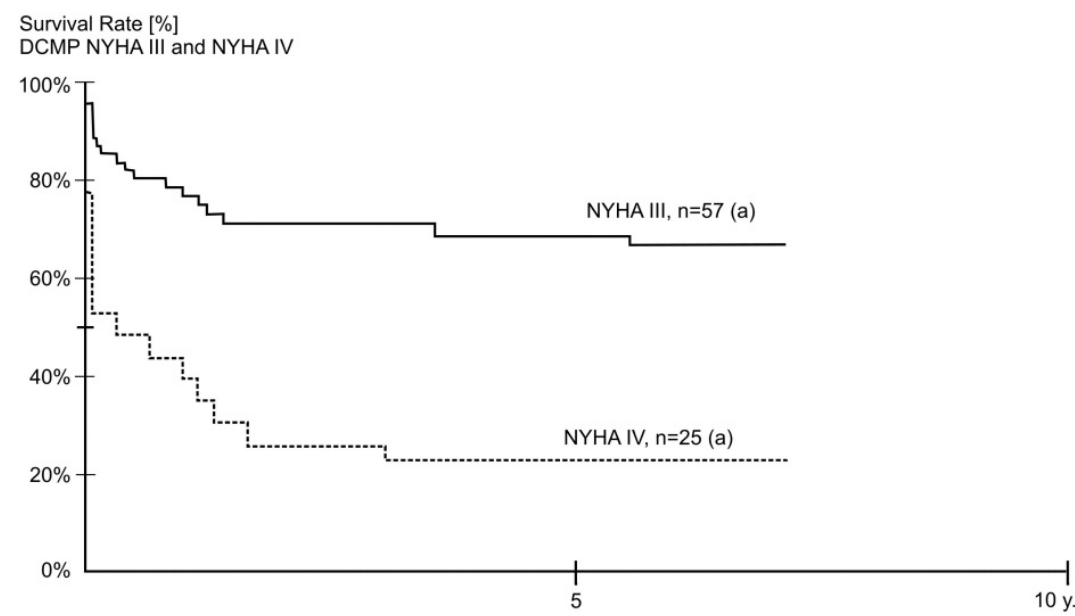

Figure 4. Kaplan-Meier statistics of the event-free survival after dynamic cardiomyoplasty according to pre-operative New York Heart Association functional class (upper curve NYHA III, lower curve NYHA IV) (a) Chachques, 1997, [37]

using different stimulation modes by synchronizing the electrical stimulation of the muscle wrap to the heart in 1:1 and 1:2 mode (stimulations bursts per heart beat). In 1:2 mode after 10 years of DCMP, there is a survival of about $40 \%$ while in 1:1 there is no survivor. A muscle damage as shown in the histology (figure 11, chapter 2.5, [5]) using also a 1:1 stimulation pattern may be the reason of this insufficient result.

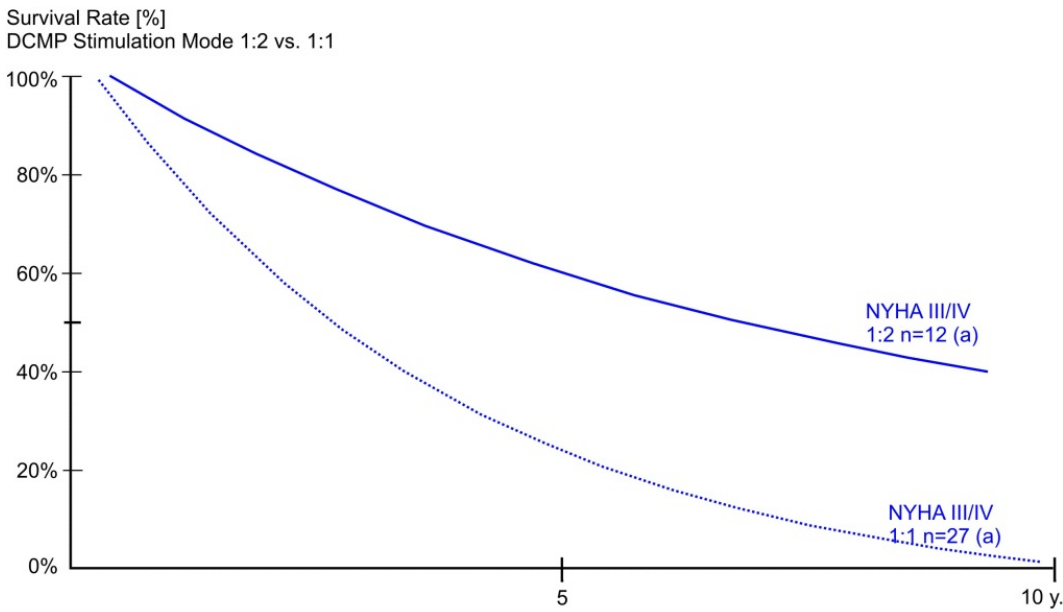

Figure 5. Survival rate of DCMP procedures 10 years after different synchronization modes with the heart contractions. $1: 2$ synchronization results in a $40 \%$ survival, while in a 1:1 mode there was no survivor. (a) Benicio et al. 2003, [20] 
The highest survival rate, upper curve in figure 3 (a), has been reported by Rigatelli et. al 2003 [118]. They applied the lowest mean pulse frequency of all investigators and used a day and night regime with a myostimulator on at day and off at night.

\subsection{NYHA - Class}

In order to determine the best course of therapy, physicians often assess the stage of heart failure according to the New York Heart Association (NYHA) functional classification system. This system relates symptoms to everyday activities and the patient's quality of life.

- Class I (Mild): No limitation of physical activity. Ordinary physical activity does not cause undue fatigue, palpitation, or dyspnea (shortness of breath).

- Class II (Mild): Slight limitation of physical activity. Comfortable at rest, but ordinary physical activity results in fatigue, palpitation or dyspnea

- Class III (Moderate): Marked limitation of physical activity. Comfortable at rest, but less than ordinary activity causes fatigue, palpitation, or dyspnea

- Class IV (Severe): Unable to carry out any physical activity without discomfort. Symptoms of cardiac insufficiency at rest, if any physical activity is undertaken.

In 101 from 139 publications about clinical DCMP authors report about the efficacy of DCMP on the clinical severity in heart failure using the classification of the New York Heart Association (NYHA). The DCMP outcome is reported between 1989 and 2009.

In figure 6 the higher bars in all cases represent the pre-operative NYHA-class and the lower bars show the post-operative results. In summary there is a significant improvement from NYHA $3.26 \pm 0.63$ to $1.69 \pm 0.34(\mathrm{p}<0.05$, figure 7$)$.

Pre- and postoperative NYHA classification per publication

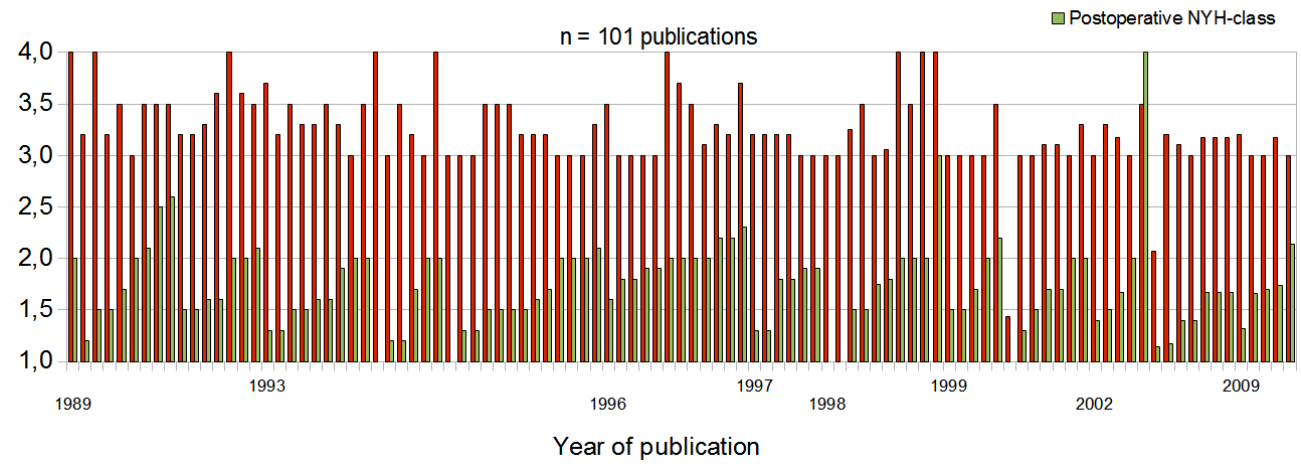

Figure 6. Clinical outcome between 1989 and 2009 evaluating 101 reports from literature shows an improvement of NYHA from pre-operatively 3.26 to post-operatively $1.69(p<0.05)$. 
Pre- and postoperative NYHA-classification

$\mathrm{n}=101$ publication

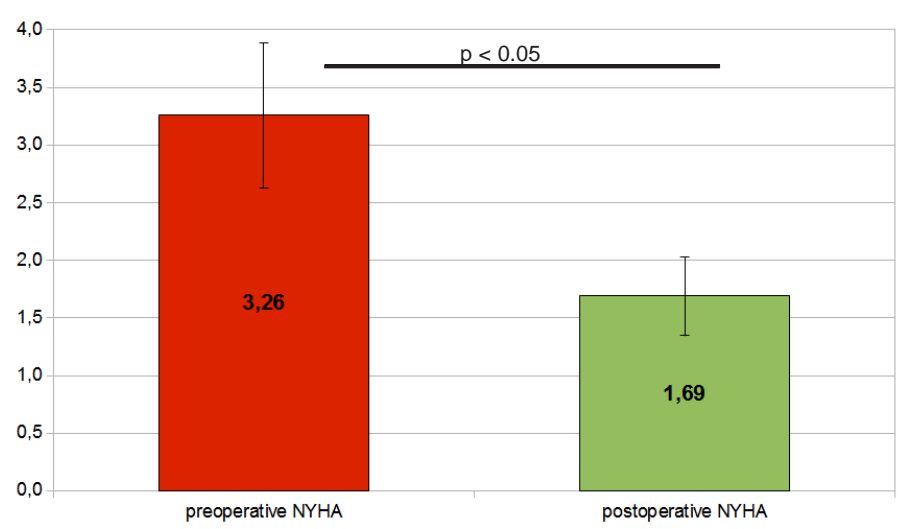

Figure 7. Mean values of the pre-operative (left) and post-operative (right) NYHA-classes $(p<0.05)$.

\subsection{Hospitalization rate}

Evaluating data from 264 patients of 7 publications [31], [35], [40], [96], [118], [136], [138], the pre-operative hospitalization rate was $2.79 \pm 0.83$ days/year. The post-operative hospitalizationrate of DCMP patients was significantly decreased with $0.48 \pm 0.23$ days/year (Figure 8).

\section{Hospitalization}

Pre- and postoperative data from 264 patients

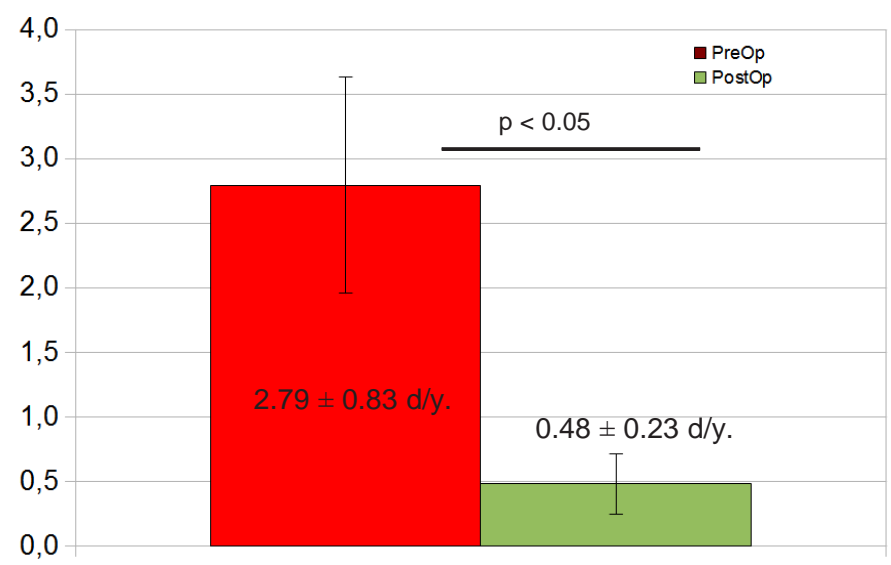

Figure 8. Mean values of the pre-operative (left) and post-operative (right) hospitalization $(p<0.05)$. 


\subsection{Ejection Fraction (EF)}

According to the clinical improvement documented by the NYHA-decline in figure 6, there is an increase of the ejection fraction (EF) of the left heart ventricle from $21.8 \pm 4.5$ to $28.9 \pm 5.9$ $(p<0.05)$. Figure 9 demonstrates an overview of the ejection fraction $(E F)$ of 89 DCMP relevant reports.

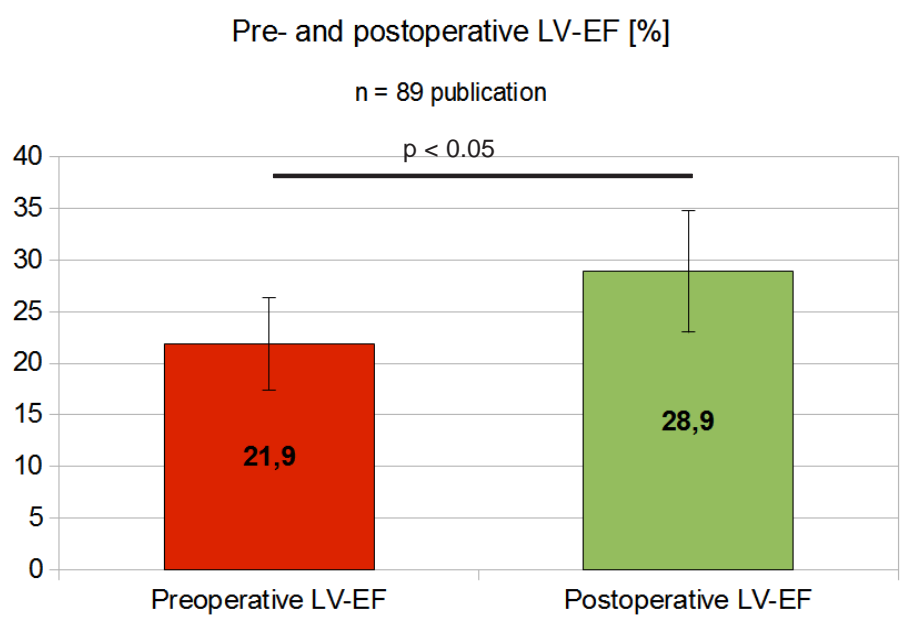

Figure 9. Ejection fraction (EF) after DCMP improved from 21.9 to $28.9 \%$

\subsection{PV-loop evaluation}

The conductance catheter method visualizes an impressive documentation of DCMP's clinical efficacy. It is performed by heart catheterization where a conductance catheter is placed along the longitudinal axis of the left heart ventricle (LV). It enables a real time volumetry of the stroke volume of the LV by recording the changes of intra-ventricular blood conductivity caused by a volume reduction (stroke volume). A simultaneous measurement of the LV's pressure allows generating pressure-volume loops in real time. The area surrounded by the loop represents the stroke work of the left heart ventricle. Thus the influence of an activated DCMP on the hemodynamic of the LV can be demonstrated as shown in figure 10 ( $n=9$ patients). A stimulated DCMP enhances the stroke work of the left ventricle.

In three patients A, B and C (Figure 11, [74]), left ventricular pressure-volume loops and relations performed by the conductance method are recorded before the cardiomyoplasty procedure and 1 year after surgery. As demonstrated by example in the baseline panel for patient A, multiple pressure- volume loops are used to measure end-systolic pressure-volume 

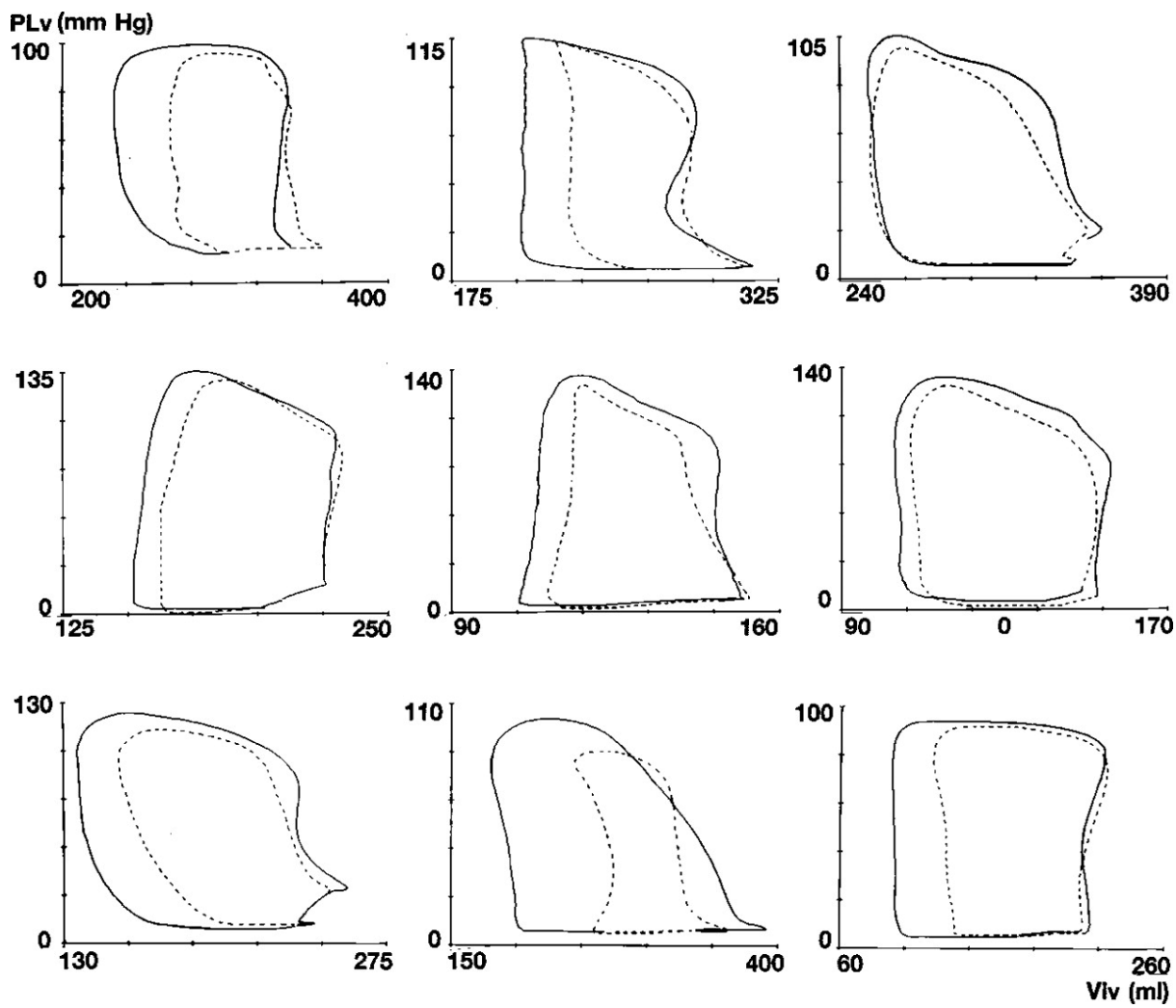

Figure 10. Pressure-volume-loops of 9 patients. The dotted lines represent non-supported and the solid lines show DCMP-supported heart cycles. Vlv expresses the volume of the left ventricle and Plv represents left ventricular pressure. (Schreuder et al.1995 [130])

relation (ESPVR) and diastolic pressure-volume relation (DPVR), defining the active and passive limits of cardiac performance, respectively.

Summarizing the results of Kass et al., the most important finding is a leftward shift of the PVloop, indicating a volume reduction of the dilated, failing heart. This reverse remodelling improves left ventricular performance.

\subsection{Histology}

Dynamic cardiomyoplasty patients had an initial clinical improvement followed by a decrease in cardiac failure indices mostly in a 1:1 stimulation mode [20]. A histopathological study of the skeletal muscle was undertaken by Gutierrezz et al. 2001 [5] to explain this. Latissimus dorsi fragments from 15 patients submitted to dynamic cardiomyoplasty in a 1:1 conditioning were analysed by light microscopy. The interval between surgery and obtaining the specimens (13 from necropsies, two from heart transplants) ranged from 37 days to 6 years. Nuclear 


\section{BASELINE}

PATIENT A

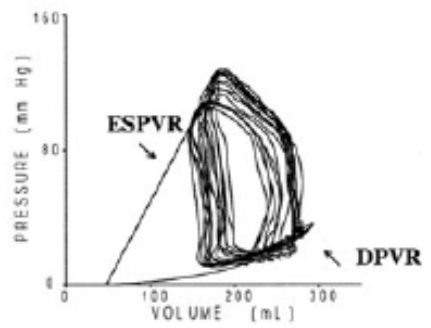

1-YEAR FOLLOW UP

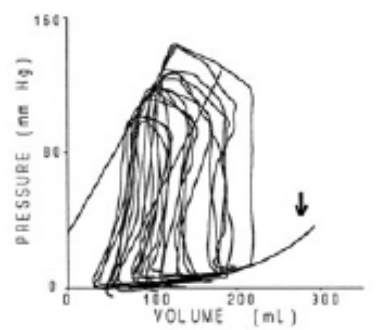

PATIENT B
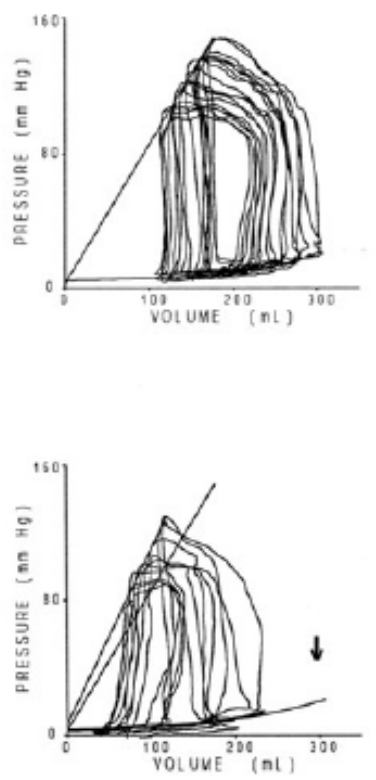

PATIENT C
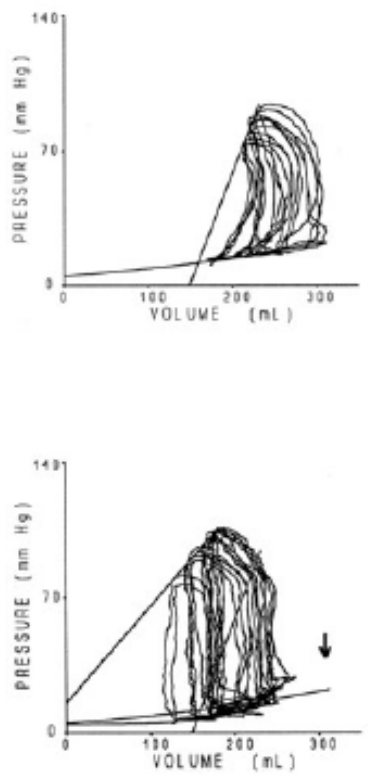

Figure 11. Effect of cardiomyoplasty on cardiac function by pressure volume relations one year after the operative DCMP procedure [74].

clumps and internalization, the presence of round fibres, inflammation, and fibrosis were analysed semi-quantitatively; the thickness of muscle fibres and the percentage of tissue fat were measured by image analysis. The quantitative data were also compared, in 12 cases, with gender- and age-matched necropsy controls. The mean thickness of muscle fibres in cases and controls was $27.21 \pm 5.33$ and $40.84 \pm 9.42 \mu$, respectively $(\mathrm{p}=0.001)$. The percentage of tissue fat in cases and controls was $12.04 \pm 12.66 \%$ and $0.93 \pm 0.91 \%$, respectively ( $p=0.008)$. Accordingly, a negative correlation was found between the duration of graft usage and the mean diameter of fibers, characterizing muscle atrophy $(\mathrm{R}=-0.66, \mathrm{p}=0.01)$. The longer the post-surgical period, the more intense the degenerative lesions. This study shows that skeletal muscle used in human dynamic cardiomyoplasty may atrophy and be replaced by fat when stimulation is synchronized to every cardiac beat [20]. These findings could play a role in explaining the longterm results in DCMP procedures as shown in Fig.5 chapter 1.2.1 with no survivors after 10 years of an electrical stimulation in a 1:1 mode. 


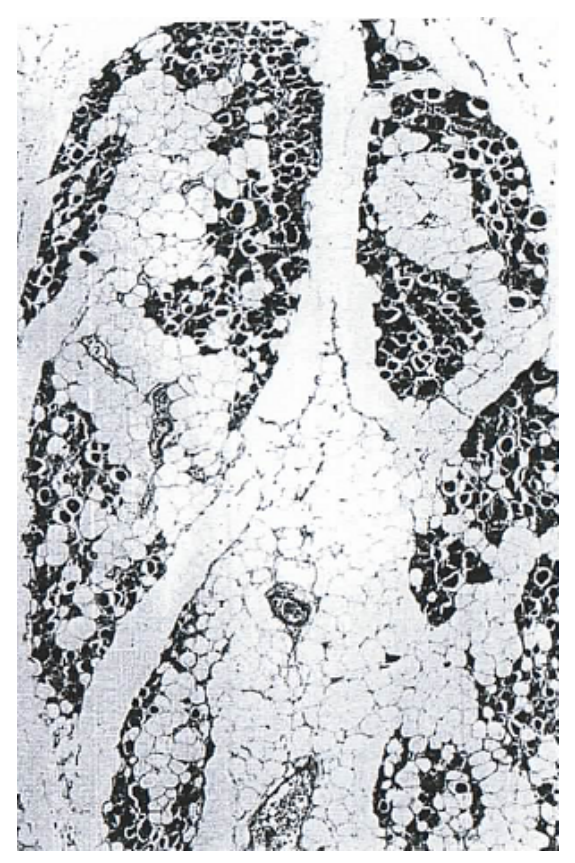

Figure 12. Histology of severe muscle damage is demonstrated using an 1:1 over stimulation. (Gutierrez et al. J Pathol 2001; 194: 116-121) [5]

\section{DCMP in comparison to other clinical treatment options for patients with end-stage heart failure}

\subsection{Medical treatment}

The only prospective randomized study comparing DCMP with the medical treatment is CSMART (Cardiomyoplasty Skeletal Muscle Assist Randomized Trial, [145]). All 103 patients suffered from cardiac failure of NYHA III. C-SMART showed that after 6 months quality of life and sub-maximal physical performance was increased significantly. The main limitation of this study was the short observation time of 6 months. This American study was finished due to the inability to recruit further patients. After these 6 months survival rate did not differ significantly. Due to the knowledge that the DCMP is effective after a longer post-operative period interval we have to rely on retrospective studies only including DCMP patients [20], [118] and medical treated over more than 4 years ([23], [146], [147], [148]). The most favourable medical therapy in NYHA III was comparable to the best results of DCMP patients in the same NYHA class. Summarizing the results of these studies comparing DCMP with medical treatment, following statements can be made:

1. As long as medical treatment is effective, it should be continued. 
2. If medical therapy in NYHA III gets insufficient and patients are going to move towards NYHA IV, a DCMP is indicated. The poor results of a medical treatment applied in NYHA IV is visible in the lowermost curve of figure 13 (f).

3. Patients having been in NYHA IV and recovered to NYHA III are candidates for a DCMP as well.

4. When a DCMP is stimulated by a stimulation pattern with less stimulation pulses, the surgical treatment might become superior to a medical treatment in future (compare topmost curve of figure 13 (a) stimulated with less pulses and using a day and night regime, having no stimulation at night.)

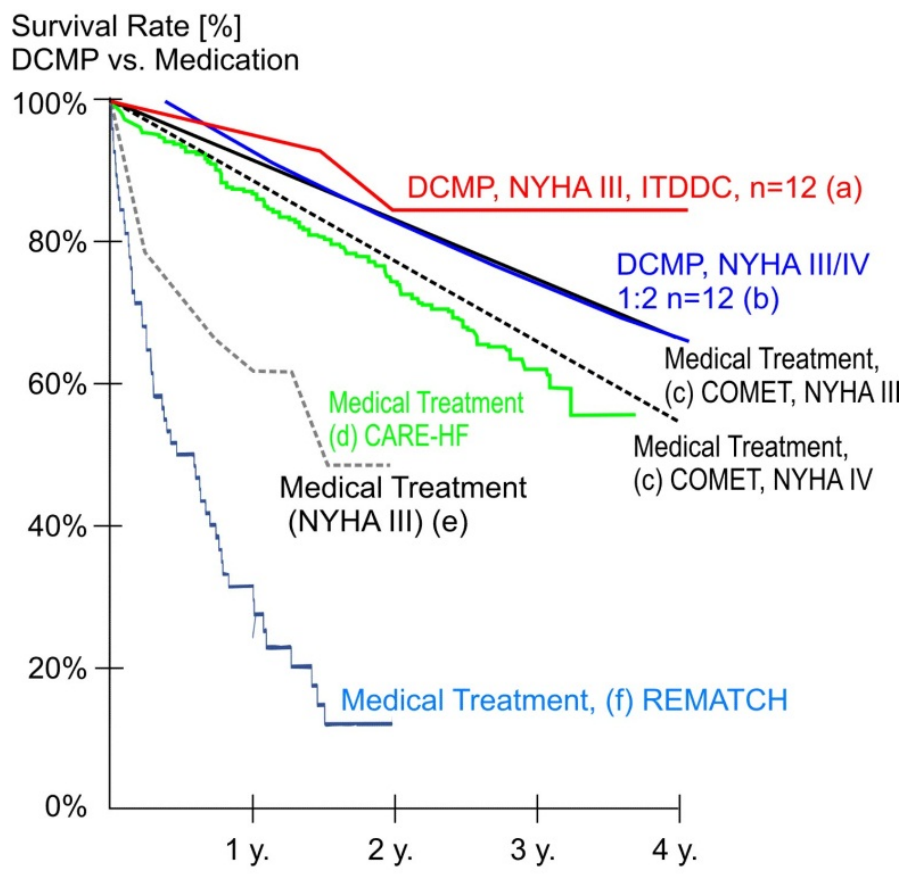

Figure 13. Clinical efficacy of the DCMP (NYHA III/IV, 1:2) in comparison to medical treatment options. (a) Rigatelli, 2002, [118] (b) Benicio, 2003, [20] (c) COMET, Poole-Wilson, 2003 [146] (d) CARE-HF, Cleland, 2005 [148] (e) Bocchi, 1996, [23] (f) REMATCH, Rose, 2001, [147]

\subsection{Cardiac resynchronization therapy (CRT)}

Comparing survival rate of DCMP and cardiac resynchronization therapy (CARE-HF, CRTgroup, [148]), some authors found superior and others equivalent results. The DCMP procedure is more invasive and expensive than a CRT. But indication for a CRT is a heart failure in combination with a desynchronization of the left and right ventricle (left or right bundle branch 
block). Additionally CRT is not effective in one third of these patients. Those are candidates for a DCMP.

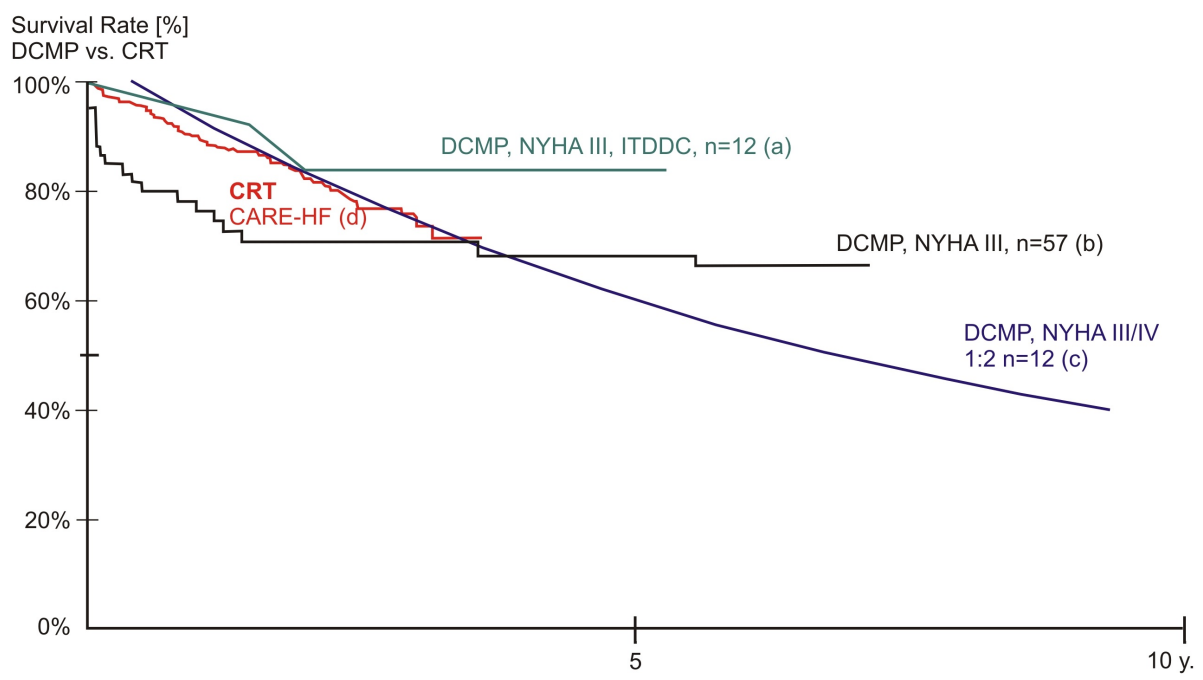

Figure 14. Efficacy of the DCMP in comparison to the cardiac resynchronisation therapy (CRT) in patients with bundle branch blocks. (a) Rigatelli, 2002 [118], (b) Chachques 1997, [37], (c) Benicio, 2003 [20], (d) CARE-HF Cleland, 2005 [148]

\subsection{Heart transplantation}

Comparing clinical results from the DCMP to those from the heart transplantation (HTX), their survival rates are comparable (figure 15, (a,b,c) vs. (d) [ISHLT, Heart Transplantation, Annual Report 2011 [149])). Objection however is, HTX is mainly suitable to NYHA class IV and DCMP to NYHA III. Taking in account the tremendous lack of donor hearts, it is to consider to apply the DCMP as early as possible in the non-effective medical treatment of NYHA III patients, to avoid a manifest stadium NYHA IV. Furthermore patients with a DCMP have no contraindication for HTX procedure. That is why DCMP can be regarded as a bridge to transplant [2] over years. In conclusion DCMP can contribute to a therapy of end-stage heart failure postponing HTX for years.

\subsection{Left heart assist devices}

Figure 16 indicates that a therapy by left heart assist devices (LVADs) is inferior to HTX, but due to the lack of donor hearts it is often the only treatment option in severe heart failure. A DCMP in NYHA III however may postpone a LVAD or HTX procedure. A comparison of DCMP and LVADs [150] count similar limitations like mentioned in HTX above, concerning the comparison of groups with different NYHA classes. 


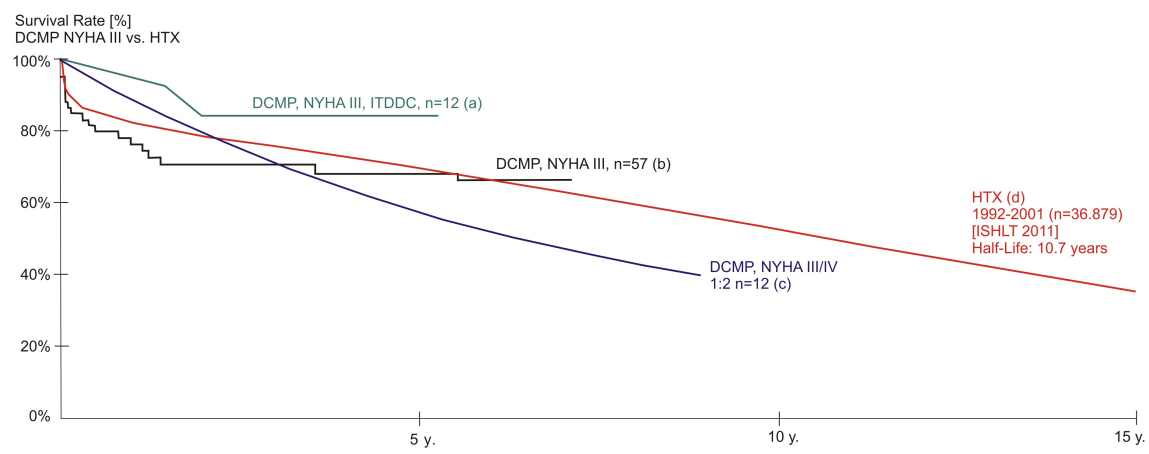

Figure 15. Clinical efficacy of a DCMP treatment in comparison to heart transplantation (HTX). (a) Rigatelli,2002, [118] (b) Chachques, 1997, [37] (c) Benicio, 2003 [20] (d) ISHLT, 2011, [149]

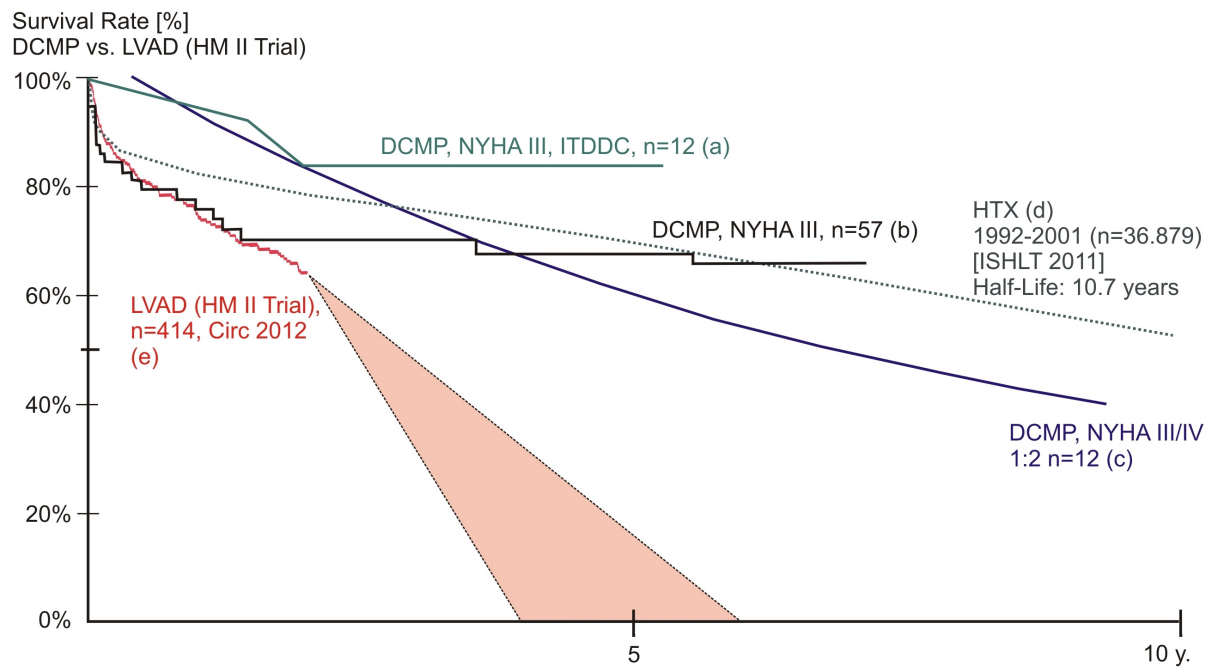

Figure 16. Efficacy of DCMP in comparison to mechanical assist devices (HeartMate II) and heart transplantation (HTX). (a) Rigatelli, 2002, [118], (b) Chachques, 1997 [37], (c) Benicio, 2003 [20], (d) ISHLT, 2011, [149] (e) Park, 2012, [150]

\subsection{Stem cell therapy}

The stem cell therapy of the human myocardium with mesenchymal stem cells (MSCs) has been evaluated in several clinical studies [151], [152]. The MSCs were applied intracoronarilly after myocardial infarction, and intra-myocardially solely and in combination with aorto- coronary bypass-surgery [153]. Thereby the ejection fraction (EF) of the left heart ventricle was seldom enhanced by more than $5 \%$ in the long time. The therapeutic effect never lasted longer than 6 to 9 months which was due to the disappearance of the MSCs 
from the myocardium within several months. Thereafter MSC's were found predominantly in liver and spleen. Thus DCMP treatment might be superior to a MSC's therapy, however there are not enough comparative clinical data yet. A combination of both seems favourable. An additive therapeutic effect specially with a stem cell transforming into cardiomyocytes and a permanent homing within the myocardium might enhance this therapy (Guldner et al. 2006, [154], 2009, [155]).

\section{Summarizing appraisal of the clinical efficacy from DCMP}

Evaluating 139 papers from literature about clinical dynamic cardiomyoplasty, DCMP showed to be effective accordingly to survival rate, NYHA class, hospitalization rate and ejection fraction of the hemodynamic from the left heart ventricle. Survival rate was clinically relevant higher in NYHA class III than in NYHA IV (Figure 4, [37]) and additionally more patients survived synchronized in 1:2 mode than in 1:1 pacing (Fig.5, [20]). Quality of life showed to be enhanced by a decreased NYHA of 1.57 (pre-operatively NYHA $3.26 \pm 0.63$ to postoperatively NYHA $1.69 \pm 0.34[\mathrm{p}<0.05])$. The ejection fraction of the left heart ventricle was increased from $21.9 \pm 4.5 \%$ to $28.9 \pm 5.9 \%(\mathrm{p}<0.05)$. A better clinical outcome is documented in cases with a reduced electrical stimulation [4], [33], [34], [117-125] accompanied with a day and night regime. A higher stimulation frequency might result in a muscle damage [5]. Dynamic cardiomyoplasty in comparison to other treatment options for end-stage heart failure like heart transplantation, resynchronization therapy, mechanical left ventricular assist devices and stem cell therapy has a clearly defined therapeutic indication. These are patients with a non-pharmacologically treatable heart failure of the NYHA class III and the nonresponders of the resynchronization therapy (CRT). Due to poor therapeutic results, NYHA IV class patients are not to be considered for a DCMP.

\section{Rational of pre-stimulation}

Enhanced capillary density in skeletal muscle, induced by different stimulation patterns, has been well investigated in small animals [156], [157] and only a few investigations are in big animals [11]. But these experiments seldomly correlate capillary density with blood flow. Thus, an evaluation of blood flow, and capillary density of a clinically feasible two weeks electrically in-situ-conditioning in latissimus dorsi muscle (LDM) was investigated at rest and exercise in human sized animals. In five adult female Boer goats $(52 \pm 9 \mathrm{~kg})$, the left LDM (group I) was stimulated in-situ electrically over 14 days $(10 \mathrm{~Hz}, 2-5 \mathrm{~V}, 12 \mathrm{~h} /$ day, $1 \mathrm{~h}$ on- $1 \mathrm{~h}$ off). The right LDM served as control (group II). After conditioning, the LDMs blood flow was measured at rest and exercise ( electric muscle stimulation over 10 minutes) by an ultrasonic flow probe around the A. thoracodorsalis. Muscle samples of different regions of LDM were harvested to evaluate the capillary to fiber ratio, mean diameter of the muscle fibers and their myosin heavy chain composition (type I/II). 


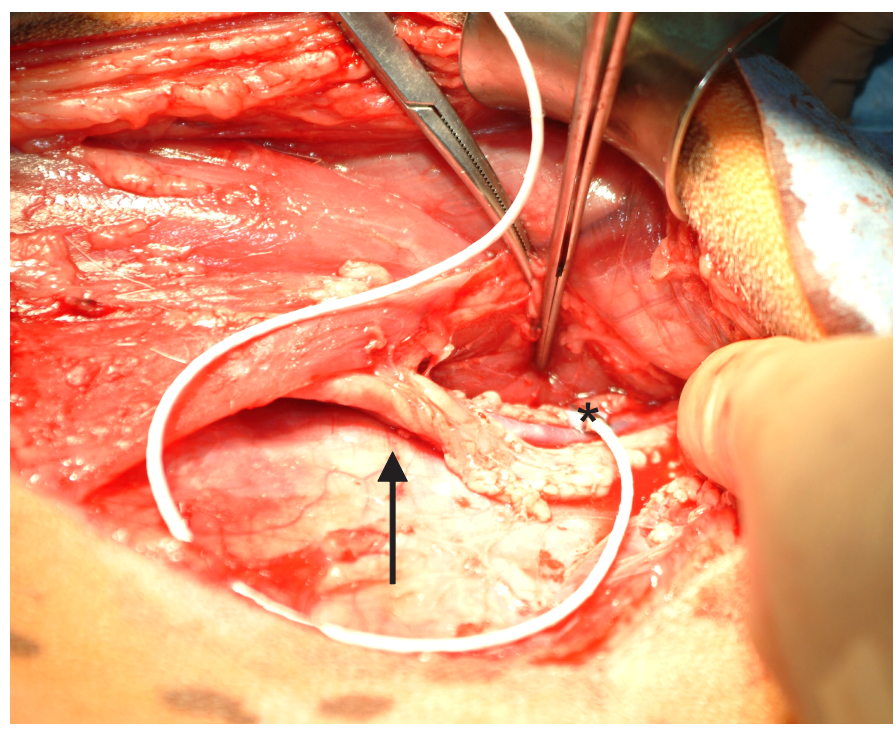

Figure 17. Operative situs in a goat during flow evaluation. The neuro-vascular bundle including the arteria thoracodorsalis leading to the latissimus dorsi muscle is demonstrated (arrow). The flow probe ${ }^{*}$ ) is situated around the arteria thoraco-dorsalis.

\section{Blood Flow in LDM under Work and Rest}
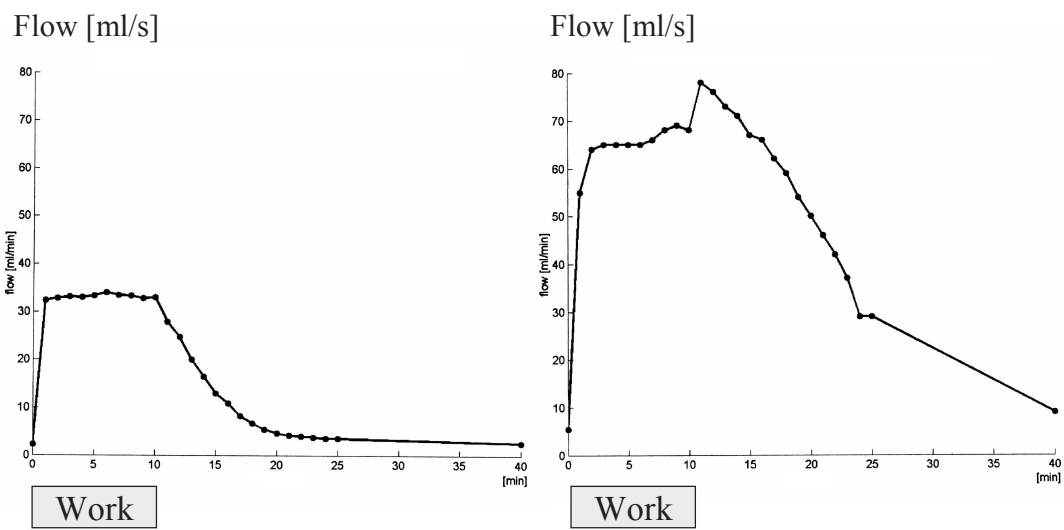

Figure 18. Blood flow within the Arteria thoraco-dorsalis of a non pre-stimulated LDM in a goat in-situ (left) in comparison to the same setting 14 days after electrically pre-stimulation of LDM in-situ (right) The pre-stimulated LDM (right) showed a higher blood flow under work conditions during a 10 minutes burst stimulation (work). 


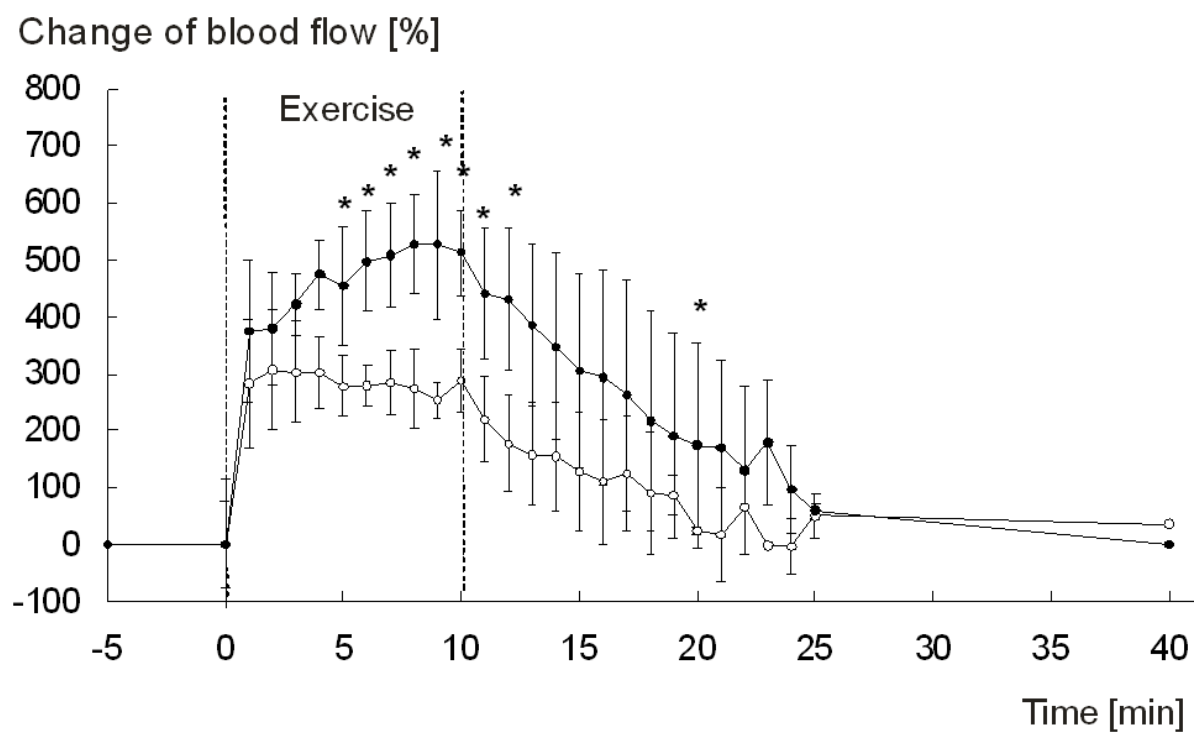

Figure 19. Change of blood flow [\%] in arteria thoracodorsalis of non- (white spots)- and pre-stimulated (black spots) $\operatorname{LDM}\left(p \leq 0.05^{\star}\right)$ under rest, exercise (stimulation) and recovery. The two weeks stimulated muscle $(n=5)$ shows a significant higher blood flow under exercise and recovery $\left(^{*}\right)$.

In group I, the pre-stimulated muscle (black spotted curve) shows an increased mean blood flow from $5.0 \pm 2.4 \mathrm{ml} / \mathrm{min}$ at rest to $30.2 \pm 2.7 \mathrm{ml} / \mathrm{min}$ under exercise. In group II, blood flow was $5.1 \pm 2.8 \mathrm{ml} / \mathrm{min}$ at rest and $19.9 \pm 0.9 \mathrm{ml} / \mathrm{min}$ under exercise. Therefore flow under exercise increased to $51.8 \%(\mathrm{p} \leq 0.01)$.

\subsection{Collaterals}

Within latissimus dorsi muscle there exist two arterial territories. A proximal one supported by the thoracodorsal artery and a distal territory supplied by perforating arteries deriving from intercostal arteries. Mobilization of the latissimus dorsi muscle as a functional graft necessarily involves division of perforating arteries that enter the distal portion of the muscle causing an ischemic tissue with a loss in function.

Between the two arterial territories anastomotic connections are well described by Salmons et.al 1998 [9]. In clinical applications, the existence of anastomotic connections offers the prospect of maintaining flow to the distal part of the grafted muscle. Electrical stimulation enhances blood flow through these anastomoses (Tang et al, 1998 [10]) demonstrated in a sheep model that a pre-stimulation of LDM in situ over two weeks increases blood flow in the distal part of LDM to a normal range while a reduction of flow by $50 \%$ was found in the untreated muscle. Own experience with pre-stimulated LDM in situ in goats confirm these findings. Prestimulated LDM's distal part looked well perfused after dissection but ischemic without prestimulation. We conclude, electrical pre-stimulation of the latissimus dorsi muscle in situ 
reduces the acute distal ischemia of LDM caused by surgical manipulations, and promotes subsequent recovery of blood flow.

In conclusion, applying pre-stimulation in-situ before a DCMP procedure might result in a relevant functional advantage and might prevent muscle damage in the distal muscle tissue of the LDM.

\subsection{Capillary density}

Experimental own data from big animal experiments in Fig.20 and Fig.21 and experimental papers of others dealing with muscle powered cardiac assist show that a pre-stimulation of the LDM in-situ enhances LDM's capillarization.

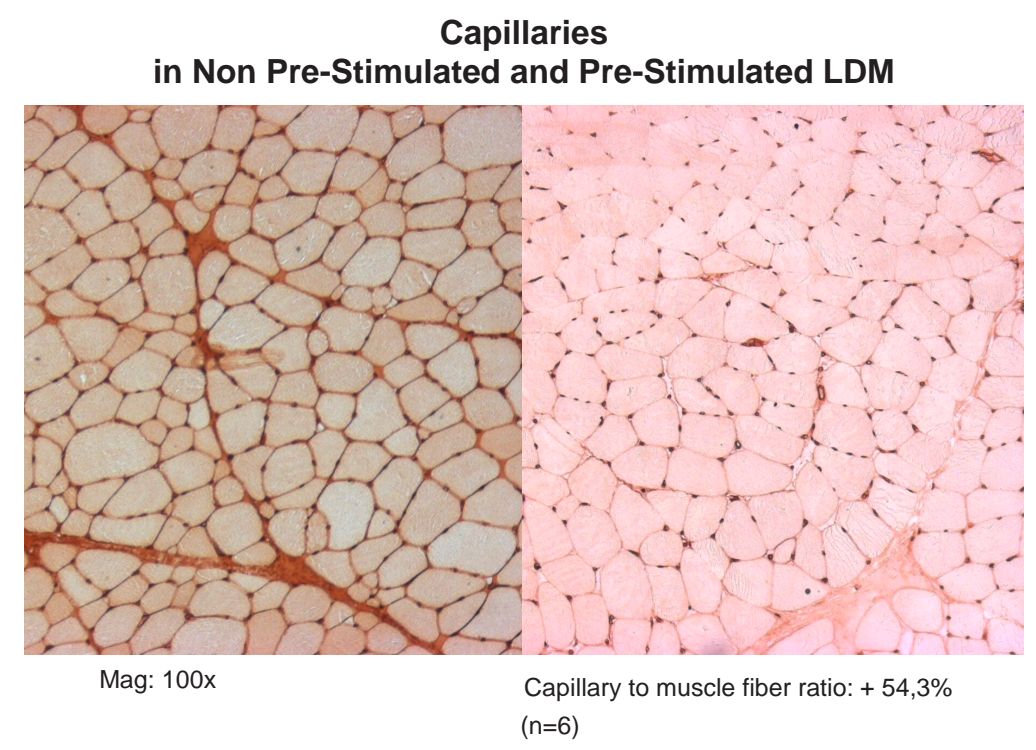

Figure 20. Histologic visualization of cross-section areas from LDMs muscle fibers surrounded by capillaries (black dots), in the stimulated muscle (right) exists a higher number of capillaries than in the non-stimulated LDM (left). 


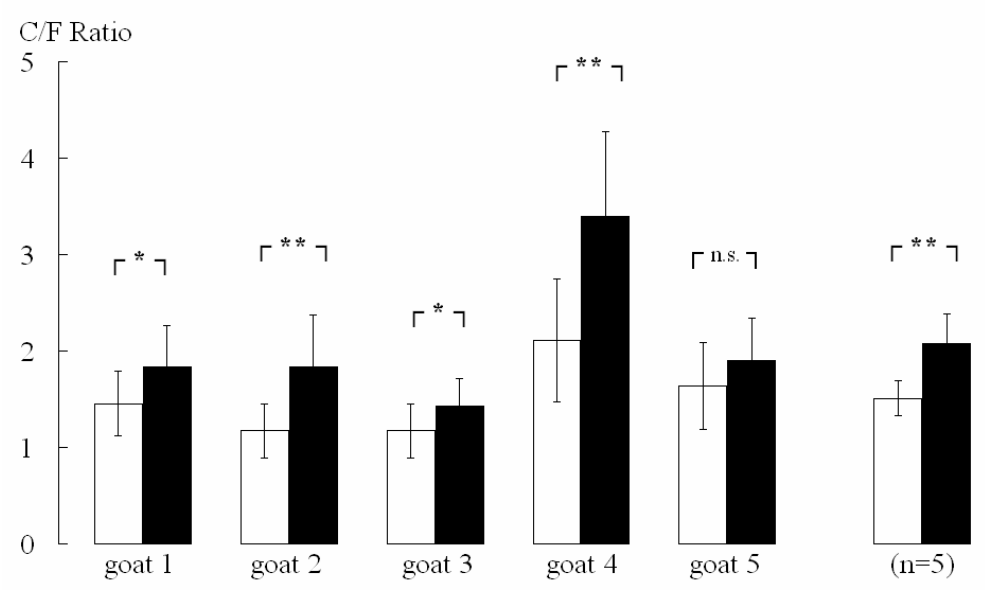

$\mathrm{C} / \mathrm{F}$ ratio in muscular tissue in five boore goats of non (white block)- and pre-stimulated (black block) LDM ( $p \leq 0.05^{\star} ; p \leq 0.01^{\star *}$, n.s. = not significant;).

Figure 21. 14 days of electrical stimulation increased the capillary to fiber ratio in goat's LDM ( $n=5)$ to $38 \%$ (black columns) in comparison to the non-stimulated contra- lateral LDM control (white columns). ( ${ }^{\star} p<0.05 ;{ }^{* *} p<0.01$; n.s. not significant)

Ischemic damage in the latissimus dorsi muscle may limit the success of cardiomyoplasty. Electrical pre-stimulation of the muscle in situ is known to enhance capillarization and thoracodorsal perfusion to the distal latissimus dorsi muscle immediately after grafting. Use of a pre-stimulated graft may therefore improve the outcome of skeletal muscle cardiac assistance (Tang et. al,1998, [10])

\section{Closed-Loop Controlled Stimulation (CLC-Stimulation)}

Since the basic experimental investigations of Salmons [7] and Pette [3], [8] it was evident, that the number of electrical pulses to a muscle fibre determines its fibre type. They showed that it is possible to transform a fast twitching fatigable IIa muscle into a fatigue resistant type I fibre muscle by increasing the number of pulses within a defined stimulation pattern. At the first glance it seemed to be ideal to substitute a damaged non-fatigable heart muscle by a slow twitching non-fatigable skeletal muscle. However, this dream was not to fulfil the expectations of muscle powered cardiac assistance clinically due to a tremendous loss of power in type I fibre muscles combined with a reduced contraction velocity. Nevertheless the DCMP showed to be effective clinically in certain limits as shown before.

Experimental investigations of Lopez-Guajardo et al. 2001 [158] demonstrated that a mean pulse reduction within certain limit results in a strong and non-fatigable muscle. But there was 
a limitation: the time of usage of this non-fatigable type II a muscle was restricted. Otherwise the muscle transformation would continue into type I fibres with all the negative consequences of power loss and a decreased contraction velocity. Therefore a controlled pulse management is mandatory to keep non-fatigable type IIa muscle fibres. This restriction in pulses however, goes along with a time-wise limited usage for a cardiac support. This fact has major implications for a restricted usage in muscle powered cardiac assist with no blood contact like the DCMP and even more in muscular blood pumps [159-161].

To fulfil these demands in electrically stimulated muscular cardiac support to maintain a nonfatigable strong muscle with a preserved contraction velocity, myostimulators are mandatory to enable a closed-loop controlled stimulation.

\subsection{Technical basics for a closed-loop controlled muscle stimulation}

In order to protect the assisting muscle, the new Microstim myostimulator will prevent chronic overstimulation which results in an undesired muscle fiber transformation and degeneration. The fiber transformation to type I would lead to a subsequently reduced contraction velocity and muscle force accompanied by a reduced cardiac support with structural and functional muscle damage.

A closed-loop is designed to limit the amount of applied stimulation pulses below a certain maximum value of mean stimulation frequency over a given period, e.g. $0.7 \mathrm{~Hz}$ mean stimulation frequency within $24 \mathrm{~h}$. This closed-loop is used to maintain the fast and powerful twitching type Ila muscle fibres needed for a sufficient muscle powered cardiac assistance.

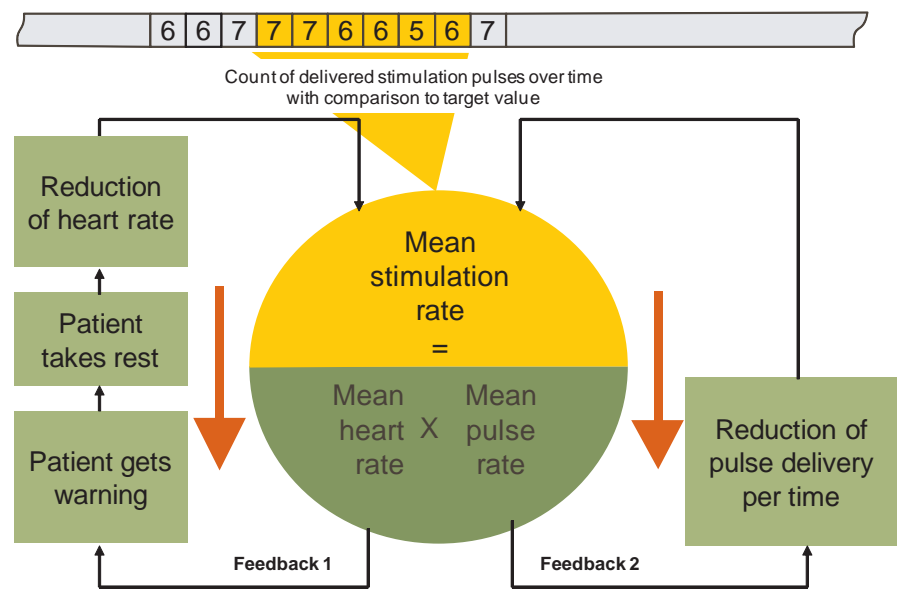

Figure 22. Closed-loop control to prevent muscular overstimulation. In feedback path 1, the patient receives a warning message via RF from the implanted myostimulator to a wearable patient monitor. Feedback path 2 intrinsically reduces the pulse delivery in accordance to programmed parameters. 
In two groups of goats, skeletal muscle ventricles (SMVs) were shaped intra-thoracically [159], [160]. In group A $(n=6)$ goat's LDM was not pre-stimulated and SMVs contracted by bursts of a mean pulse frequency of $5 \mathrm{~Hz}$. This mean frequency of approximately $5 \mathrm{~Hz}$ has been used clinically in more than 1000 cases up to now, resulting in severe muscle damage as shown above in chapter 2.2. Group B, LDM with pre-stimulation over 14 days as shown above and with a controlled stimulation with a mean pulse frequency not exceeding $1 \mathrm{~Hz}$ mean pulse frequency showed a preserved muscle tissue (figure 23, right). This new stimulation regime in group B became feasible by the newly available myostimulator with an integrated feature for muscle protection (MyoSen ${ }^{\circledR}$ Myostim GmbH, Wismar, Germany).

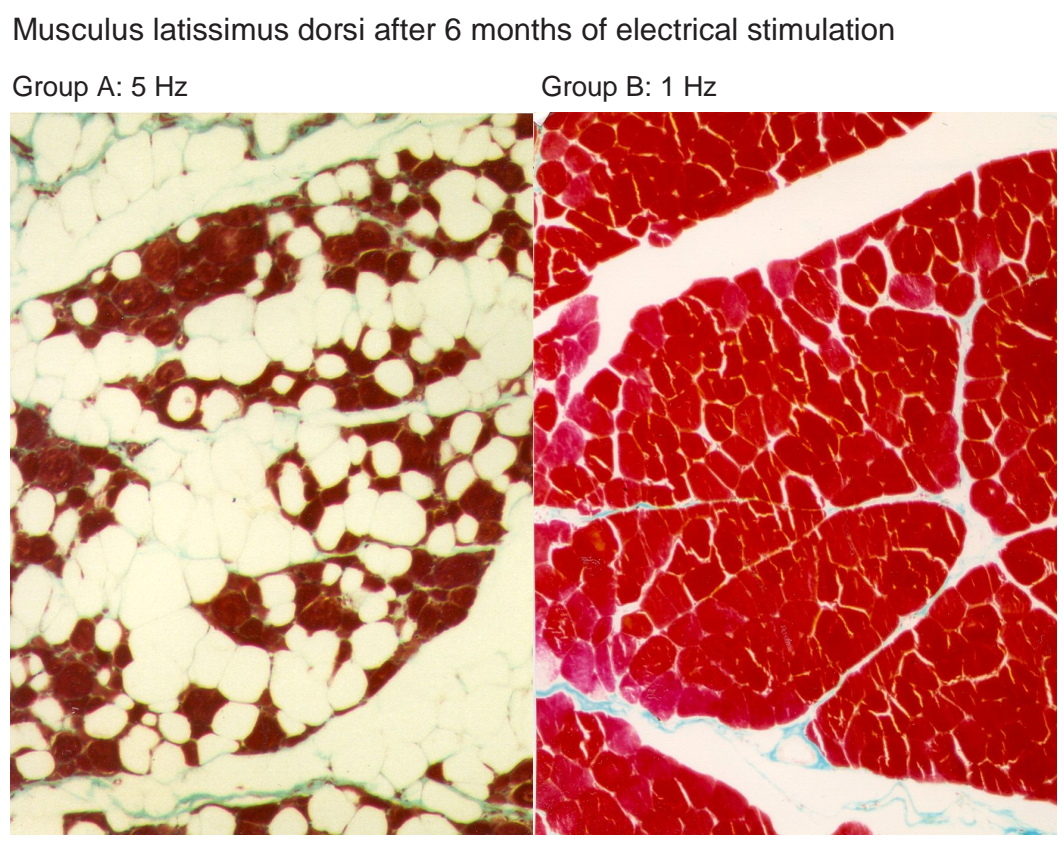

Figure 23. Histology of LDM 6 months after electrical stimulation with $5 \mathrm{~Hz}$ and without pre-stimulation resulting in severe muscle damage (left) and LDM with pre-stimulation over 14 days and closed-loop controlled stimulation with a mean pulse frequency of $1 \mathrm{~Hz}$ and preserved muscle tissue.

\section{DCMP vs. CLC- DCMP - Clinical implications}

This special kind of "electrical tissue engineering" of the LDM in situ 14 days before wrapping the LDM around the heart and a controlled electrical stimulation pattern with a reduced mean pulse frequency minor $1 \mathrm{~Hz}$ should significantly increase the clinical efficacy of DCMP which has been described above. The new pre-stimulated, controlled cardiomyoplasty (CLC-CMP) 
or its combination with intra-myocardial injections of adult stem cells (Stem Cell Cardiomyopexy) might open new fields in the therapy of pharmacologically untreatable heart failure.

Comparing DCMP vs. CLC- DCMP, the expected efficacy of CLC- DCMP, well based on facts as shown above, should become an effective and reliable treatment option for end-stage heart failure with much better therapeutic results as shown in clinical DCMP up to now. A combination with an intramyocardial stem cell therapy is desirable [154], [155].

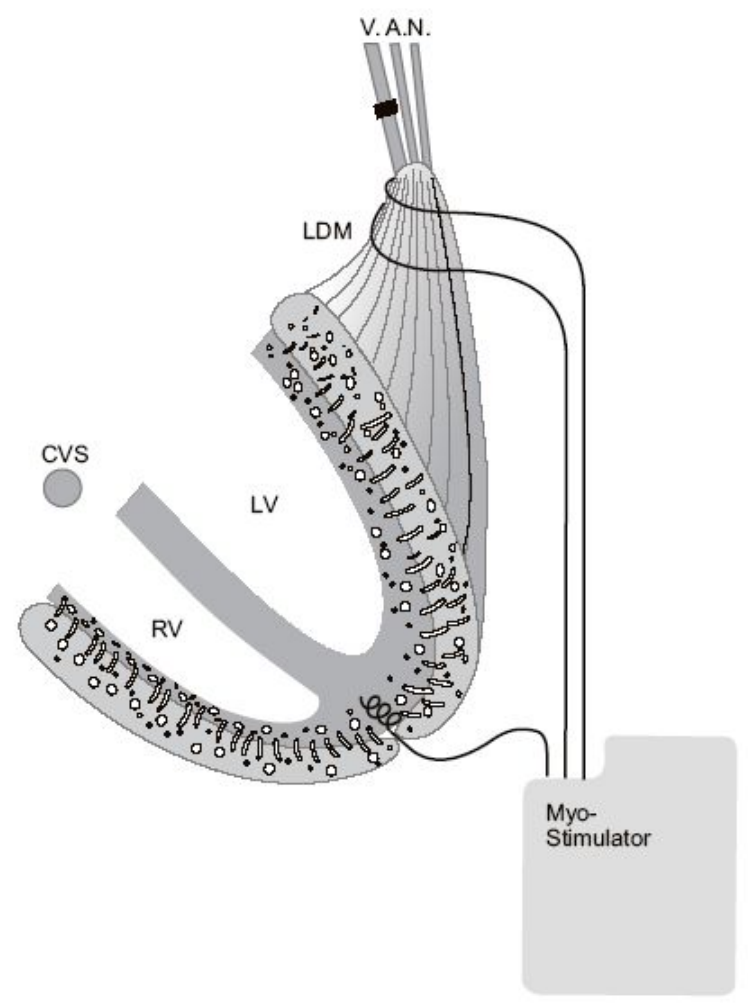

Figure 24. Pre-stimulated and such hypercapillarized muscle, wrapped around the heart for indirect revascularization and girdling using a stimulation with a reduced number of pulses as a controlled cardiomyoplasty (CLC-DCMP).

\section{Conclusion}

DCMP has been effective clinically but did not fulfil the therapeutic expectations. Additional treatment processes like pre-stimulation in situ and CLC-DCMP-pacing may increase clinical efficacy for patients with a refractory medical treatment in NYHA III in future. 


\section{Acknowledgements}

We thank Prof. Dr. Petra Margaritoff, Hamburg University of Applied Sciences, Germany for critical reading of the manuscript.

\section{Author details}

Norbert W. Guldner ${ }^{1 *}$, Peter Klapproth ${ }^{2}$ and Hans-H. Sievers ${ }^{1}$

*Address all correspondence to: Guldner@uni-luebeck.de

1 Clinic of Cardiac Surgery, University of Lübeck, Germany

2 Microstim GmbH, Wismar, Germany

\section{References}

[1] A. Carpentier and J. C. Chachques, "Myocardial substitution with a stimulated skeletal muscle: first successful clinical case.," Lancet, vol. 1, no. 8440, p. 1267, Jun. 1985.

[2] J. C. Chachques, O. J. Jegaden, V. Bors, T. Mesana, C. Latremouille, P. A. Grandjean, J. N. Fabiani, and A. Carpentier, "Heart transplantation following cardiomyoplasty: a biological bridge," Eur.J.Cardiothorac.Surg., vol. 33, no. 1010-7940 (Print), pp. 685-690, Apr. 2008.

[3] D. Pette, "Fiber transformation and fiber replacement in chronically stimulated muscle," J Heart Lung Transplant, vol. 11, pp. 299-305, 1992.

[4] G. Rigatelli, U. Carraro, M. Barbiero, R. Riccardi, F. Cobelli, and M. Gemelli, “A Review of the Concept of Circulatory Bioassist Focused on the 'New' Demand Dynamic Cardiomyoplasty: The Renewal of Dynamic Cardiomyoplasty?," Angiology, vol. 54, no. 3, pp. 301-306, May 2003.

[5] P. S. Gutierrez, W. O. Pires Jr., S. K. Marie, L. F. Moreira, C. Mady, M. L. Higuchi, N. A. Stolf, and J. A. Ramires, "Histopathological findings in skeletal muscle used in human dynamic cardiomyoplasty," J.Pathol., vol. 194, no. 0022-3417 (Print), pp. 116121, May 2001.

[6] J. H. Davidse, F. H. van der Veen, C. M. Lucas, O. C. Penn, M. J. Daemen, and H. J. Wellens, "Structural alterations in the latissimus dorsi muscles in three patients more than 2 years after a cardiomyoplasty procedure.," European heart journal, vol. 19, no. 2, pp. 310-8, Feb. 1998. 
[7] S. Salmons and F. Sreter, "Significance of impulse activity in the transformation of skeletal muscle type," Nature, vol. 263, pp. 30-34, 1976.

[8] D. Pette, "Historical Perspectives: plasticity of mammalian skeletal muscle," J Appl Physiol, vol. 90, no. 3, pp. 1119-24, 2001.

[9] S. Salmons, A. Tang, J. Jarvis, H. Degens, M. Hastings, and T. Hooper, "Morphological and functional evidence, and clinical importance, of vascular anastomoses in the latissimus dorsi muscle of the sheep," J Anat, vol. 193, no. 1, pp. 93-104, 1998.

[10] A. Tang, J. Jarvis, T. Hooper, and S. Salmons, "Observation and basis of improved blood flow to the distal latissimus dorsi muscle: a case for electrical stimulation prior to grafting," Cardiovascular Research, vol. 40, pp. 131-137, 1998.

[11] R. E. Klabunde, M. Anderson, William A. Locke, S. E. Ianuzzo, and C. D. Ianuzzo, "Regional blood flows in the goat latissimus dorsi muscle before and after chronic stimulation," J Appl Physiol, vol. 81, pp. 2365-2372, 1996.

[12] M. a Acker, "Dynamic cardiomyoplasty: at the crossroads.," The Annals of thoracic surgery, vol. 68, no. 2, pp. 750-5, Aug. 1999.

[13] S. D. Akhmedov, E. V. Krivoschekov, M. V. Pekarskaya, A. L. Krylov, Z. V. Vesnina, V. I. Chernov, A. M. Chernyavskiy, Y. Y. Vechersky, R. S. Karpov, E. a. Nechaev, and V. V. Pekarski, "Clinical Results of Dynamic Cardiomyoplasty," Journal of Cardiac Surgery, vol. 10, no. 5, pp. 573-579, Sep. 1995.

[14] L. . Almada, H; Molteni, "Cardiomyoplasty: Our experience after six years," Basic Appl.Myol., vol. 3, no. 4, pp. 303-306, 1994.

[15] H. Almada, L. Molteni, R. Ferreira, and D. Ortega, "Clinical experience with dynamic cardiomyoplasty.," Journal of cardiac surgery, vol. 5, no. 3, pp. 193-8, Sep. 1990.

[16] H. Almada, L. Molteni, R. Ferreira, D. Ortega, T. Cianciulli, S. Llanos, and H. Prezioso, "The value of the echo-Doppler in cardiomyoplasty procedures," J.Card Surg., vol. 6, no. 0886-0440 (Print), pp. 113-118, Mar. 1991.

[17] J. O. C. Auler and L. F. Moreira, “Anesthetic Management of Patients Undergoing Cardiomyoplasty," Anesthesiology, vol. 77, pp. 379-381, 1992.

[18] M. Barbiero, U. Carraro, R. Riccardi, A. Cotogni, and G. Ri-, “Demand Dynamic Cardiomyoplasty: Two-Year Results," Basic Appl.Myol., vol. 9, no. 4, pp. 195-206, 1999.

[19] G. Bellotti, a Moraes, E. Bocchi, S. Arie, C. Medeiros, L. F. Moreira, a Jatene, and F. Pileggi, "Late effects of cardiomyoplasty on left ventricular mechanics and diastolic filling.," Circulation, vol. 88, no. 5 Pt 2, pp. II304-8, Nov. 1993.

[20] A. Benicio, L. F. Moreira, F. Bacal, N. A. Stolf, and S. A. Oliveira, "Reevaluation of long-term outcomes of dynamic cardiomyoplasty," Ann.Thorac.Surg., vol. 76, no. 0003-4975 (Print), pp. 821-827, Sep. 2003. 
[21] A. Benicio, L. F. Moreira, F. Bacal, N. Stolf, and S. A. Oliveira, "Risk factors of mortality in nine years of follow-up after dynamic cardiomyoplasty," Rev Bras Cir Cardiovasc, vol. 18, no. 2, pp. 163-171, 2003.

[22] P. Blanc and C. Girard, "Latissimus dorsi cardiomyoplasty. Perioerative management and postoperative evolution," Chest, vol. 103, pp. 214-220, 1993.

[23] E. A. Bocchi, G. Bellotti, L. F. Moreira, F. Bacal, A. V. de Moraes, A. Fiorelli, A. Mansur, N. Stolf, A. Jatene, and F. Pileggi, "Mid-term results of heart transplantation, cardiomyoplasty, and medical treatment of refractory heart failure caused by idiopathic dilated cardiomyopathy," J.Heart Lung Transplant., vol. 15, no. 1053-2498 (Print), pp. 736-745, Jul. 1996.

[24] E. A. Bocchi, G. V. Guimaraes, L. F. Moreira, F. Bacal, A. V. de Moraes, A. C. Barreto, M. Wajngarten, G. Bellotti, N. Stolf, A. Jatene, and ., "Peak oxygen consumption and resting left ventricular ejection fraction changes after cardiomyoplasty at 6-month follow-up," Circulation, vol. 92, no. 0009-7322 (Print), pp. II216-II222, Nov. 1995.

[25] E. A. Bocchi, L. F. Moreira, A. V. de Moraes, F. Bacal, E. Sosa, N. A. Stolf, G. Bellotti, A. D. Jatene, and F. Pilleggi, "Arrhythmias and sudden death after dynamic cardiomyoplasty," Circulation, vol. 90, no. 0009-7322 (Print), pp. II107-II111, Nov. 1994.

[26] E. a Bocchi, L. F. Moreira, a V. de Moraes, G. Bellotti, M. Gama, N. a Stolf, a D. Jatene, and F. Pileggi, "Effects of dynamic cardiomyoplasty on regional wall motion, ejection fraction, and geometry of left ventricle.," Circulation, vol. 86, no. 5 Suppl, pp. II231-5, Nov. 1992.

[27] S. A. Borghetti-Maio, B. W. Romano, E. A. Bocchi, L. F. Moreira, A. C. Barreto, N. A. Stolf, G. V. Bellotti, F. Pilleggi, and A. D. Jatene, "Quality of life after cardiomyoplasty," J.Heart Lung Transplant., vol. 13, no. 1053-2498 (Print), pp. 271-275, Mar. 1994.

[28] D. M. Braile and M. J. F. Soares, “Cardiomyoplasty in 26 Patients with up to Six Years Follow-Up," Basic Appl.Myol., vol. 3, no. 4, pp. 289-302, 1993.

[29] D. Braile, P. R. Brofmann, K. Shatarov, A. S. Revishvili, L. Bokeria, and M. Schaldach, "Clinical experience with ANS controlled Cardiomyoplasty," Biomedical Research, pp. 7-9, 1996.

[30] D. M. Braile, M. F. Godoy, G. H. Thèvenard, R. S. Thèvenard, M. C. V. B. Braile, J. C. F. Leal, M. Schaldach, and H. The, "Dynamic Cardiomyoplasty: Long-Term Clinical Results in Patients With Dilated Cardiomyopathy," Ann.Thorac.Surg., vol. 69, pp. 1445-1447, 2000.

[31] A. Carpentier, J. C. Chachques, C. Acar, J. Relland, S. Mihaileanu, D. Bensasson, J. P. Kieffer, P. Guibourt, D. Tournay, and I. Roussin, "Dynamic cardiomyoplasty at seven years.," The Journal of thoracic and cardiovascular surgery, vol. 106, no. 1, pp. 42-52; discussion 52-4, Jul. 1993.

[32] U. Carraro, G. Docali, and M. Barbiero, “Demand Dynamic Cardiomyoplasty: Improved clinical benefits by non-invasive monitoring of LD flap and long- Term tun- 
ing of its Dynamic contractile characteristics by activity-rest regime," Basic Appl.Myol., vol. 8, no. 1, pp. 11-15, 2011.

[33] U. Carraro, G. Rigatelli, K. Rossini, and M. Barbiero, “Demand dynamic bio-girdling in heart failure: improved efficacy of dynamic cardiomyoplasty by LD contraction during aortic out-flow," Int.J.Artif.Organs, vol. 26, no. 0391-3988 (Print), pp. 217-224, Mar. 2003.

[34] U. Carraro, G. Docali, A. Cotogni, G. Rigatelli, D. Casarotto, and C. Muneretto, “Demand dynamic cardiomyoplasty: mechanograms prove incomplete transformation of the rested latissimus dorsi," Ann.Thorac.Surg., vol. 70, pp. 67-73, 2000.

[35] J. C. Chachques, C. Acar, M. Portoghese, D. Bensasson, P. Guibourt, P. Grare, V. A. Jebara, P. A. Grandjean, and A. Carpentier, "Dynamic cardiomyoplasty for long-term cardiac assist.," European journal of cardio-thoracic surgery: official journal of the European Association for Cardio-thoracic Surgery, vol. 6, no. 12, pp. 642-7; discussion 647-8, Jan. 1992.

[36] J. C. Chachques, P. G. Argyriadis, G. Fontaine, J.-L. Hebert, R. a Frank, N. D'Attellis, J.-N. Fabiani, and A. F. Carpentier, "Right ventricular cardiomyoplasty: 10-year follow-up.," The Annals of thoracic surgery, vol. 75, no. 5, pp. 1464-8, May 2003.

[37] J. C. Chachques, A. Berrebi, A. Hernigou, A. Cohen-Solal, T. Lavergne, J. P. Marino, N. D'Attellis, D. Bensasson, and A. Carpentier, "Study of muscular and ventricular function in dynamic cardiomyoplasty: a ten-year follow-up," J.Heart Lung Transplant., vol. 16, no. 1053-2498 (Print), pp. 854-868, Aug. 1997.

[38] J. C. Chachques and A. Carpentier, "Postoperative Management," in Cardiomyoplasty, A. Carpentier, J. C. Chachques, and P. A. Grandjean, Eds. Futura Publishing Company, Inc., 1991, pp. 131-138.

[39] J. C. Chachques, O. Jegaden, T. Mesana, Y. Glock, P. A. Grandjean, and A. F. Carpentier, "Cardiac bioassist: results of the French multicenter cardiomyoplasty study.," Asian cardiovascular \& thoracic annals, vol. 17, no. 6, pp. 573-80, Dec. 2009.

[40] J. C. Chachques, J. P. Marino, P. Lajos, R. Zegdi, N. D'Attellis, P. Fornes, J. N. Fabiani, and A. Carpentier, "Dynamic cardiomyoplasty: clinical follow-up at 12 years.," European journal of cardio-thoracic surgery: official journal of the European Association for Cardio-thoracic Surgery, vol. 12, no. 4, pp. 560-7; discussion 567-8, Oct. 1997.

[41] J. C. Chachques, a. B. A. Shafy, F. Duarte, B. Cattadori, N. Goussef, L. Shen, and A. Carpentier, "From Dynamic to Cellular Cardiomyoplasty," Journal of Cardiac Surgery, vol. 17, no. 3, pp. 194-200, Jul. 2002.

[42] V. S. Chekanov and S. Deshpande, "Cardioverter-Defibrillator implantation to safeguard against fatal arrhythmias in cardiomyoplasty patients," Basic Appl.Myol., vol. 9, no. 4, pp. 187-194, 1999. 
[43] V. S. Chekanov, S. Deshpande, D. Francischelli, P. Werner, D. Waller, and D. H. Schmidt, "Cardiomyoplasty after implantation of a pacemaker and cardioverter/ defibrillator," Ann.Thorac.Surg., vol. 66, no. 0003-4975 (Print), pp. 954-956, Sep. 1998.

[44] V. S. Chekanov, D. E. Sands, C. S. Brown, F. Brum, P. Arzuaga, S. Gava, F. P. Eugenio, V. Melamed, and H. W. Spencer, "Cardiomyoplasty: first clinical case with new cardiomyostimulator.," Asian cardiovascular $\mathcal{E}$ thoracic annals, vol. 10, no. 3, pp. 264-6, Sep. 2002.

[45] R. C. Chiu, “Dynamic cardiomyoplaty for heart failure," Br Heart J, vol. 73, pp. 1-3, 1995.

[46] R. C. Chiu, J. N. Odim, and J. H. Burgess, "Responses to dynamic cardiomyoplasty for idiopathic dilated cardiomyopathy. The McGill Cardiomyoplasty Group," Am.J.Cardiol., vol. 72, no. 0002-9149 (Print), pp. 475-479, Aug. 1993.

[47] A. Cohen-Solal, R. Choussat, J. C. Chachques, T. Laperche, B. Caviezel, M. Geneves, A. Carpentier, and R. Gourgon, "Serial assessment of cardiopulmonary exercise capacity after cardiomyoplasty for either ischemic or idiopathic dilated cardiomyopathy," Am.J.Cardiol., vol. 77, no. 0002-9149 (Print), pp. 623-627, Mar. 1996.

[48] J. I. de la Torre, D. W. Griffin, and L. O. Vasconez, "Harvesting the latissimus dorsi muscle for cardiomyoplasty.," Plastic and reconstructive surgery, vol. 105, no. 1, pp. 838, Jan. 2000.

[49] F. Delahaye, O. Jegaden, P. Montagna, P. Desseigne, P. Blanc, C. Vedrinne, P. Touboul, A. Saint-Pierre, M. Perinetti, R. Rossi, and ., "Latissimus dorsi cardiomyoplasty in severe congestive heart failure: the Lyon experience," J.Card Surg., vol. 6, no. 08860440 (Print), pp. 106-112, Mar. 1991.

[50] E. Domenegati, M. Maurelli, M. G. Chiaudani, a Pagnin, and M. Rinaldi, "Management of anesthesia during dynamic cardiomyoplasty.," Journal of clinical anesthesia, vol. 7, no. 3, pp. 177-81, May 1995.

[51] R. Driever, R. Bugenhagen, S. Fuchs, C. Minale, and H. O. Vetter, "Cardiomyoplasty: long-term results in ischemic cardiomyopathy," Int.J.Artif.Organs, vol. 24, no. 03913988 (Print), pp. 152-156, Mar. 2001.

[52] A. Dumcius and K. Salcius, "Elektrostimulated Cardiomyoplasty: From experimental to clinical studies," Pace, vol. 19, pp. 1205-1210, 1996.

[53] F.Fontaliran, J. C. Chachques, F. H. van der Veen, R. Scelsi, and A. Carpentier, "A Clinical-pathological Study 2 years following Cardiomyoplasty: Intact Latissimus Dorsi Muscle and metabolic transformation of Myofibers," Basic Appl.Myol., vol. 7, no. 6, pp. 369-373, 1997.

[54] A. P. Furnary, J. A. Magovern, I. Y. Christlieb, J. E. Orie, K. A. Simpson, and G. J. Magovern, "Clinical cardiomyoplasty: pre-operative factors associated with outcome," Ann.Thorac.Surg., vol. 54, no. 0003-4975 (Print), pp. 1139-1143, Dec. 1992. 
[55] a P. Furnary, J. S. Swanson, G. Grunkemeier, and a Starr, "Lessons learned before and after cardiomyoplasty: risk sensitive patient selection and post procedure quality of life.," Journal of cardiac surgery, vol. 11, no. 3, pp. 200-6.

[56] A. P. Furnary and J. S. Swanson, "Dynamic Cardiomyoplasty: Now and in the Future," Basic Appl.Myol., vol. 3, no. 4, pp. 307-311, 1993.

[57] A. Furnary, M. Jessup, and L. F. Moreira, "Multicenter Trial of Dynamic Cardiomyoplasty for Chronic Heart Failure," J Am Coll Cardiol, vol. 28, pp. 1175-80, 1996.

[58] P. Gerometta, S. D. Matteo, M. Agrifoglio, M. Naliato, A. Parolari, V. Arena, N. Valerio, and P. Biglioli, "Blood Flow Pattern in the Thoracodorsal Artery after Dynamic Cardiomyoplasty," Basic Appl.Myol., vol. 8, no. 1, pp. 17-20, 1998.

[59] P. A. Grandjean, "Pulse Generator System for Dynamic Cardiomyoplasty," in Cardiomyoplasty, A. Carpentier, J. C. Chachques, and P. A. Grandjean, Eds. Futura Publishing Company, Inc., 1991, pp. 123 - 130.

[60] P. A. Grandjean, M. Acker, R. Madoff, N. S. Williams, J. Woloszko, and C. Kantor, "Dynamic myoplasty: surgical transfer and stimulation of skeletal muscle for functional substitution or enhancement.," Journal of rehabilitation research and development, vol. 33, no. 2, pp. 133-44, Apr. 1996.

[61] P. A. Grandjean, L. Austin, S. Chan, B. Terpstra, and I. M. Bourgeois, "Dynamic cardiomyoplasty: clinical follow-up results," J.Card Surg., vol. 6, no. 0886-0440 (Print), pp. 80-88, Mar. 1991.

[62] P. A. Grandjean, J. C. Chachques, and O. Jegaden, “Long-term outcome of Dynamic Cardiomyoplasty in France," Basic Appl.Myol., vol. 19, no. 1, pp. 17-24, 2009.

[63] N. R. Grubb, G. R. Sutherland, C. Campanella, A. Fleming, C. J. Sinclair, and K. A. Fox, "Latissimus dorsi muscle: assessment of stimulation after cardiomyoplasty with Doppler US tissue imaging," Radiology, vol. 199, no. 0033-8419 (Print), pp. 59-64, Apr. 1996.

[64] a a Hagege, M. Desnos, J. C. Chachques, a Carpentier, F. Fernandez, F. Fontaliran, and C. Guerot, "Preliminary report: follow-up after dynamic cardiomyoplasty.," Lancet, vol. 335, no. 8698, pp. 1122-4, May 1990.

[65] A. A. Hagege, M. Desnos, F. Fernandez, B. Besse, N. Mirochnik, M. Castaldo, J. C. Chachques, A. Carpentier, and C. Guerot, "Clinical study of the effects of latissimus dorsi muscle flap stimulation after cardiomyoplasty," Circulation, vol. 92, no. 00097322 (Print), pp. II210-II215, Nov. 1995.

[66] A. Haverich and G. Watanabe, "Heart transplantation, assist devices, and crdiomyoplasty," Current Opinion in Cardiology, vol. 7, pp. 259-266, 1992. 
[67] J. Helou, Y. Misawa, J. A. Stewart, M. Colson, and R. C. Chiu, “Optimizing 'delay period' for burst stimulation in dynamic cardiomyoplasty," Ann.Thorac.Surg., vol. 59, no. 0003-4975 (Print), pp. 74-77, Jan. 1995.

[68] A. D. Jatene and L. F. Moreira, "Reply to invited letter concerning: Left ventricular function changes after cardiomyoplasty in patients with dilated cardiomyopathy (J Thorac Cardiovasc Surg 1991;102:156-7)," The Journal of thoracic and cardiovascular surgery, vol. 103, no. 3, p. 595, Mar. 1992.

[69] A. D. Jatene, L. F. Moreira, N. A. Stolf, E. A. Bocchi, P. Seferian Jr., P. M. Fernandes, H. Abensur, and P. Seferian, "Left ventricular function changes after cardiomyoplasty in patients with dilated cardiomyopathy," J.Thorac.Cardiovasc.Surg., vol. 102, no. 0022-5223 (Print), pp. 132-138, Jul. 1991.

[70] O. Jegaden, F. Delahaye, G. Finet, der Van V, P. Montagna, A. Eker, J. Ossete, R. Rossi, P. A. Saint, and P. H. Mikaeloff, "Late hemodynamic results after cardiomyoplasty in congestive heart failure," Ann.Thorac.Surg., vol. 57, no. 0003-4975 (Print), pp. 11511157, May 1994.

[71] O. Jegaden, F. Delahaye, P. Montagna, C. Vedrinne, P. Blanc, R. Rossi, A. Tabib, P. A. Saint, J. P. Delahaye, and P. H. Mikaeloff, "Cardiomyoplasty does not preclude heart transplantation," Ann.Thorac.Surg., vol. 53, no. 0003-4975 (Print), pp. 875-880, May 1992.

[72] G. Jondeau, R. Dorent, V. Bors, J. C. Dib, O. Dubourg, R. Benzidia, I. Gandjbakhch, and J. P. Bourdarias, "Dynamic cardiomyoplasty: effect of discontinuing latissimus dorsi muscle stimulation on left ventricular systolic and diastolic performance and exercise capacity.," Journal of the American College of Cardiology, vol. 26, no. 1, pp. 12934, Jul. 1995.

[73] R. Kalil-Filho, E. Bocchi, R. G. Weiss, L. Rosemberg, F. Bacal, L. F. Moreira, N. A. Stolf, A. A. Magalhães, G. Bellotti, and A. Jatene, "Magnetic resonance imaging evaluation of chronic changes in latissimus dorsi cardiomyoplasty.," Circulation, vol. 90, no. 5 Pt 2, pp. II102-6, Nov. 1994.

[74] D. a Kass, K. L. Baughman, P. H. Pak, P. W. Cho, H. R. Levin, T. J. Gardner, H. R. Halperin, J. E. Tsitlik, and M. a Acker, "Reverse remodeling from cardiomyoplasty in human heart failure. External constraint versus active assist.," Circulation, vol. 91, no. 9, pp. 2314-8, May 1995.

[75] D. S. Küçükaksu, O. Tarcan, S. Küçüker, M. A. Ozatik, Z. Sakaogullari, E. Sener, and O. Taşdemir, "Dynamic cardiomyoplasty as a biomechanic bridge to heart transplantation.," Heart E lung: the journal of critical care, vol. 32, no. 6, pp. 407-11, 2003.

[76] E. Lalinde, J. Sanz, a Bazán, a Ballesteros, F. Mesa, J. Elejabeitia, V. Paloma, and J. Herreros, "The use of latissimus dorsi muscle flap in reconstructive heart surgery.," Plastic and reconstructive surgery, vol. 94, no. 3. pp. 490-5, Sep-1994. 
[77] R. Lange, J. Brachmann, and S. Hagl, "Stellenwert der dynamischen Kardiomyoplastik [Value of dynamic cardiomyoplasty]," Z.Kardiol., vol. 85 Suppl 4, no. 0300-5860 (Print), pp. 49-58, 1996.

[78] R. Lange and S. Hagl, "Dynamic cardiomyoplasty: how well does it work?," Eur.Heart J., vol. 18, no. 0195-668X (Print), pp. 191-197, Feb. 1997.

[79] R. Lange, F. U. Sack, B. Voss, R. De Simone, a Nair, M. Thielmann, J. Brachmann, F. Fleischer, and S. Hagl, "Dynamic cardiomyoplasty: indication, surgical technique, and results.," The Thoracic and cardiovascular surgeon, vol. 43, no. 5, pp. 243-51, Oct. 1995.

[80] R. R. Lazzara and D. R. Trumble, "Clinical and Experimental Effects of the Unstimulated (Static) Right Latissimus Dorsi Cardiomyoplasty on Left Ventricular Function," Basic Appl.Myol., vol. 3, no. 4, pp. 281-288, 1993.

[81] A. Lehmann and K. Faust, "Dynamic cardiomyoplasty in patients with end-stage heart failure: anaestetic considerations," Br J Anaesth, vol. 82, pp. 140-143, 1999.

[82] Lorusso R, Marchini A, Bianchetti F, Curnis A, Visioli O, and Zogno M., "Cardiomyoplasty and implantable cardioverter defibrillator: efficacy and safety of concomitant device implantation: sudden death and cardiomyoplasty," J Card Surg., vol. 13, no. 2, pp. 150-5, 1998.

[83] R. Lorusso, G. Coletti, a Della Valle, G. Steffenino, G. Aliprandi, and O. Alfieri, "Right latissimus dorsi cardiomyoplasty in diaphragm eventration and cardiac malposition.," The Annals of thoracic surgery, vol. 60, no. 2, pp. 452-4, Aug. 1995.

[84] R. Lorusso, A. Curnis, C. Struble, L. Sandrelli, and O. Alfieri, "Bacterial infection of cardiomyostimulator abdominal pocket following cardiomyoplasty procedure: an original approach to preserve synchronous muscle stimulation.," Journal of cardiac surgery, vol. 10, no. 4 Pt 1, pp. 358-62, Jul. 1995.

[85] R. Lorusso, E. Milan, M. Volterrani, R. Giubbini, F. H. van der Veen, J. J. Schreuder, A. Picchioni, and O. Alfieri, "Cardiomyoplasty as an isolated procedure to treat refractory heart failure," Eur.J.Cardiothorac.Surg., vol. 11, no. 1010-7940 (Print), pp. 363372, Feb. 1997.

[86] R. Lorusso, C. Struble, F. Bianchetti, a Marchini, a Curnis, and O. Alfieri, "Management of pacing system related complications in patients undergoing dynamic cardiomyoplasty.," Pacing and clinical electrophysiology: PACE, vol. 22, no. 1 Pt 1, pp. 116-8, Jan. 1999.

[87] R. Lorusso, M. Zogno, G. La Canna, M. Metra, L. Sandrelli, V. Borghetti, F. Maisano, and O. Alfieri, "Dynamic cardiomyoplasty as an effective therapy for dilated cardiomyopathy.," Journal of cardiac surgery, vol. 8, no. 2, pp. 177-83, Mar. 1993. 
[88] R. Lorusso, F. H. V. D. Veen, O. Alfieri, and C. S. Division, "Recent Findings on Cardiomyoplasty Management and Mechanisms of Action: Implications for Patient Selection, and Postoperative Care," Basic Appl.Myol., vol. 7, no. 1, pp. 15-22, 1997.

[89] C. M. Lucas, F. H. van der Veen, E. C. Cheriex, V. van Ommen, O. C. Penn, and H. J. Wellens, "The importance of muscle relaxation in dynamic cardiomyoplasty.," Pacing and clinical electrophysiology: PACE, vol. 15, no. 10 Pt 1, pp. 1430-6, Oct. 1992.

[90] G. J. Magovern Sr. and K. A. Simpson, "Clinical cardiomyoplasty: review of the tenyear United States experience," Ann.Thorac.Surg., vol. 61, no. 0003-4975 (Print), pp. 413-419, Jan. 1996.

[91] G. J. Magovern, F. R. Heckler, S. B. Park, I. Y. Christlieb, G. A. Liebler, J. A. Burkholder, T. D. Maher, D. H. Benckart, G. J. Magovern Jr., and R. L. Kao, "Paced skeletal muscle for dynamic cardiomyoplasty," Ann.Thorac.Surg., vol. 45, no. 0003-4975 (Print), pp. 614-619, Jun. 1988.

[92] G. J. Magovern, F. R. Heckler, S. B. Park, I. Y. Christlieb, G. J. Magovern Jr., R. L. Kao, D. H. Benckart, G. Tullis, E. Rozar, G. A. Liebler, and ., "Paced latissimus dorsi used for dynamic cardiomyoplasty of left ventricular aneurysms," Ann.Thorac.Surg., vol. 44, no. 0003-4975 (Print), pp. 379-388, Oct. 1987.

[93] G. J. Magovern, S. B. Park, R. L. Kao, I. Y. Christlieb, and G. J. Magovern Jr., “Dynamic cardiomyoplasty in patients," J.Heart Transplant., vol. 9, no. 0887-2570 (Print), pp. 258-263, May 1990.

[94] J. a Magovern, T. J. Hunter, J. C. Cardone, and I. Y. Christlieb, “Long-term results of right latissimus dorsi cardiomyoplasty.," Journal of cardiac surgery, vol. 11, no. 4, pp. 264-70.

[95] J. a Magovern, G. J. Magovern, T. D. Maher, D. H. Benckart, S. B. Park, and I. Y. Christlieb, "Operation for congestive heart failure: transplantation, coronary artery bypass, and cardiomyoplasty.," The Annals of thoracic surgery, vol. 56, no. 3. pp. 41824; discussion 424-5, Sep-1993.

[96] J. a Magovern, G. J. Magovern, M. a Palumbi, and J. E. Orie, "Surgical therapy for congestive heart failure: indications for transplantation versus cardiomyoplasty.," The Journal of heart and lung transplantation: the official publication of the International Society for Heart Transplantation, vol. 11, no. 3 Pt 1. pp. 538-44.

[97] T. Mesana, S. Bauer, T. Caus, C. Pomane, A. Mouly, and J. Monties, "Circulatory Assist Techniques After Cardiomyoplasty-Determinants for Clinical Outcome and Late Consequences," ASAIO, vol. 41, pp. M469-M472, 1995.

[98] Y. Misawa, B. D. Mott, J. O. Lough, and R. C. Chiu, "Pathologic findings of latissimus dorsi muscle graft in dynamic cardiomyoplasty: clinical implications," J.Heart Lung Transplant., vol. 16, no. 1053-2498 (Print), pp. 585-595, Jun. 1997. 
[99] L. Molteni, H. Almada, and R. Ferreira, "Synchronously stimulated skeletal muscle graft for left ventricular assistance. Case report.," The Journal of thoracic and cardiovascular surgery, vol. 97, no. 3, pp. 439-46, Mar. 1989.

[100] L. F. Moreira, A. Benicio, F. Bacal, E. A. Bocchi, N. A. Stolf, and S. A. Oliveira, "Determinants of long-term mortality of current palliative surgical treatment for dilated cardiomyopathy," Eur J Cardiothorac Surg, vol. 23, pp. 756-764, 2003.

[101] L. F. Moreira, E. a Bocchi, F. Bacal, N. a Stolf, G. Bellotti, and a D. Jatene, "Present trends in clinical experience with dynamic cardiomyoplasty.," Artificial organs, vol. 19, no. 3. pp. 211-6, Mar-1995.

[102] L. F. Moreira, E. A. Bocchi, and N. A. Stolf, “Dynamic Cardiomyoplasty in the treatment of dilated cardiomyopathy: Current results and perspectives," J Card Surg., vol. 11, pp. 207-216, 1996.

[103] L. F. Moreira, E. a Bocchi, N. a Stolf, F. Pileggi, and a D. Jatene, "Current expectations in dynamic cardiomyoplasty.," Ann.Thorac.Surg., vol. 55, no. 1. pp. 299-303, Jan-1993.

[104] L. F. Moreira, P. Seferian Jr., E. A. Bocchi, P. M. Pego-Fernandes, N. A. Stolf, A. C. Pereira-Barretto, and A. D. Jatene, "Survival improvement with dynamic cardiomyoplasty in patients with dilated cardiomyopathy," Circulation, vol. 84, no. 0009-7322 (Print), pp. III296-III302, Nov. 1991.

[105] L. F. Moreira, N. a Stolf, E. a Bocchi, F. Bacal, P. M. Pêgo-Fernandes, H. Abensur, J. C. Meneghetti, and a D. Jatene, "Clinical and left ventricular function outcomes up to five years after dynamic cardiomyoplasty.," The Journal of thoracic and cardiovascular surgery, vol. 109, no. 2, pp. 353-62; discussion 362-3, Feb. 1995.

[106] L. F. Moreira, N. A. Stolf, E. A. Bocchi, A. C. Pereira-Barretto, J. C. Meneghetti, M. C. Giorgi, A. V. Moraes, J. J. Leite, P. L. da Luz, and A. D. Jatene, "Latissimus dorsi cardiomyoplasty in the treatment of patients with dilated cardiomyopathy," Circulation, vol. 82, no. 0009-7322 (Print), pp. IV257-IV263, Nov. 1990.

[107] L. F. Moreira, N. a Stolf, D. M. Braile, and a D. Jatene, "Dynamic cardiomyoplasty in South America.," The Annals of thoracic surgery, vol. 61, no. 1, pp. 408-12, Jan. 1996.

[108] L. F. Moreira, N. A. Stolf, and A. D. Jatene, "Benefits of cardiomyoplasty for dilated cardiomyopathy," Semin.Thorac.Cardiovasc.Surg., vol. 3, no. 1043-0679 (Print), pp. 140-144, Apr. 1991.

[109] T. H. Nguyenn and T.-A. hhhhoang, "Latissimus Dorsi Cardiomyoplasty:Radiographic Findingss," American Roentgen Ray Society, vol. 150, pp. 545-547, 1988.

[110] G. Nikolić, “Narrow capture beat.," Heart \& lung: the journal of critical care, vol. 33, no. 3, pp. 194-5.

[111] J. N. Odim, J. H. Burgess, B. H. Williams, P. E. Blundell, M. a Rabinovitch, J. a Stewart, J. O. Lough, and R. C. Chiu, "Pathophysiology of dynamic cardiomyoplasty: a 
clinico-pathological case study.," Journal of cardiac surgery, vol. 5, no. 4, pp. 336-46, Dec. 1990.

[112] A. Peix, J. Tain, C. Cabrera, F. Dortico, D. Garcia-Barreto, L. Rodriguez, and A. M. Maltas, "Radionuclide ventriculography in dynamic cardiomyoplasty," J.Nucl.Biol.Med., vol. 38, no. 0368-3249 (Print), pp. 535-539, Dec. 1994.

[113] V. V. Pekarsky, S. D. Akhmedov, I. a Dubrovsky, a V. Baturin, E. V. Krivoschekov, a N. Rizhikh, and M. V. Pekarskaya, "Optimal electrical stimulation for latissimus dorsi muscle after cardiomyoplasty.," Journal of cardiac surgery, vol. 8, no. 2, pp. 172-6, Mar. 1993.

[114] J. Peteiro, C. Struble, N. Vazquez, and A. Castro-Beiras, "Spontaneous reversal of a cardiomyostimulator to asynchronous mode.," Pacing and clinical electrophysiology: PACE, vol. 19, no. 3, pp. 367-9, Mar. 1996.

[115] P. A. Poole-Wilson, K. Swedberg, J. G. F. Clemand, A. Di Lenarda, P. Hanrath, M. Komejda, J. Lubsen, B. Lutiger, M. Metra, W. J. Remme, C. Torp-Pedersen, A. Scherhag, and A. Skene, "Comparison of carvedilol and metoprolol on clinical outcomes in patients with chronic heart failure in the Carvedilol Or Metoprolol European Trial (COMET): randomised controlled trial," The Lancet, vol. 362, pp. 7-13, 2003.

[116] T. S. Rector, D. Benditt, J. C. Chachques, R. C. Chiu, F. Delahaye, M. Jessup, G. Kirkorian, G. Thiene, and J. Titus, "Retrospective risk analysis for early heart-related death after cardiomyoplasty. The Worldwide Cardiomyoplasty Group," J.Heart Lung Transplant., vol. 16, no. 1053-2498 (Print), pp. 1018-1025, Oct. 1997.

[117] G. L. Rigatelli, U. Carraro, M. Barbiero, M. Zanchetta, and G. Rigatelli, “New hopes for dynamic cardiomyoplasty from use of Doppler flow wire in evaluation of demand stimulation," J.Cardiovasc.Surg.(Torino), vol. 43, no. 0021-9509 (Print), pp. 6770, Feb. 2002.

[118] G. Rigatelli and M. Barbiero, "Skeletal muscle cardiocirculatory - Assist by demand dynamic cardiomyoplasty: 5-Year results," Basic Appl.Myol., vol. 12, no. 3, pp. 91-95, 2002.

[119] G. Rigatelli, M. Barbiero, A. Cotogni, A. Bandello, R. Riccardi, and U. Carraro, “'Demand' stimulation of latissimus dorsi heart wrap: experience in humans and comparison with adynamic girdling," The Annals of Thoracic Surgery, vol. 76, no. 5, pp. 15871592, Nov. 2003.

[120] G. Rigatelli and U. Carraro, "Demand cardiomyoplasty: Dynamic girdling is superior to Adynamic Girdling," Basic Appl.Myol., vol. 13, no. 2, pp. 89-93, 2003.

[121] G. Rigatelli and U. Carraro, "Correlations between time, Latissimus dorsi wrap properties and systolic assistance in demand dynamic cardiomyoplasty?," Basic Appl.Myol., vol. 10, no. 5, pp. 249-251, 2000.

[122] G. Rigatelli, M. Barbiero, G. Rigatelli, R. Riccardi, F. Cobelli, A. Cotogni, A. Bandello, and U. Carraro, "Maintained benefits and improved survival of dynamic cardiomyo- 
plasty by activity-rest stimulation: 5-year results of the Italian trial on 'demand' dynamic cardiomyoplasty.," European journal of cardio-thoracic surgery: official journal of the European Association for Cardio-thoracic Surgery, vol. 23, no. 1, pp. 81-5, Jan. 2003.

[123] G. Rigatelli and U. Carraro, "Latissimus Dorsi tetanic fusion frequency in clinical settings: Monitoring fast to slow muscle transformation during follow-up of Demand Dynamic Cardiomyoplasty," Basic Appl.Myol., vol. 19, no. 1, pp. 25-30, 2009.

[124] G. Rigatelli, U. Carraro, M. Barbiero, M. Zanchetta, K. Dimopoulos, F. Cobelli, R. Riccardi, and G. Rigatelli, "Activity-rest stimulation protocol improves cardiac assistance in dynamic cardiomyoplasty.," European journal of cardio-thoracic surgery: official journal of the European Association for Cardio-thoracic Surgery, vol. 21, no. 3, pp. 478-82, Mar. 2002.

[125] G. Rigatelli, U. Carraro, R. Riccardi, and G. Rigatelli, “Demand dynamic biogirdling: ten-year results.," The Journal of thoracic and cardiovascular surgery, vol. 137, no. 1, pp. e58-9, Jan. 2009.

[126] S. Salmons and J. C. Jarvis, "Cardiomyoplasty: A Look at the Fundamentals," in Cardiomyoplasty, A. F. Carpentier, J. C. Chachques, and P. A. Grandjean, Eds. Futura Publishing Company, Inc., 1991, pp. 3-17.

[127] J. J. Schreuder, F. H. van der Veen, F. Delahaye, O. Alfieri, O. Jegarden, R. Lorusso, J. R. Jansen, V. van Ommen, G. Finet, and H. J. Wellens, “Congestive Heart Failure: Beat-to-Beat Analysis of Left Ventricular Pressure-Volume Relation and Stroke Volume by Conductance Catheter and Aortic Modelflow in Cardiomyoplasty Patients," Circulation, vol. 91, no. 7, p. 2010:2017, 1995.

[128] J. J. Schreuder, F. H. van der Veen, E. T. van der Velde, F. Delahaye, O. Alfieri, O. Jegaden, R. Lorusso, J. R. Jansen, S. a Hoeksel, G. Finet, M. Volterrani, H. G. Kaulbach, J. Baan, and H. J. Wellens, "Left ventricular pressure-volume relationships before and after cardiomyoplasty in patients with heart failure.," Circulation, vol. 96, no. 9, pp. 2978-86, Nov. 1997.

[129] J. J. Schreuder, F. H. van der Veen, E. T. van der Velde, F. Delahaye, O. Alfieri, O. Jegaden, R. Lorusso, J. R. Jansen, O. van V, G. Finet, and ., "Beat-to-beat analysis of left ventricular pressure-volume relation and stroke volume by conductance catheter and aortic Modelflow in cardiomyoplasty patients," Circulation, vol. 91, no. 00097322 (Print), pp. 2010-2017, Apr. 1995.

[130] J. J. Schreuder, F. H. van der Veen, E. T. van der Velde, F. Delahaye, O. Alfieri, O. Jegaden, R. Lorusso, J. R. Jansen, O. van V, G. Finet, ., O. Jegarden, V. van Ommen, and H. J. Wellens, "Congestive Heart Failure: Beat-to-Beat Analysis of Left Ventricular Pressure-Volume Relation and Stroke Volume by Conductance Catheter and Aortic Modelflow in Cardiomyoplasty Patients," Circulation, vol. 91, no. 7, p. 2010:2017, Apr. 1995. 
[131] M. Smink and F. H. van der Veen, "Imaging of skeletal muscle contraction after Cardiomyoplasty," Basic Appl.Myol., vol. 9, no. 5, pp. 223-227, 1999.

[132] O. Tasdemir, S. D. Küçükaksu, K. M. Vural, F. S. Katircioglu, E. Kütük, and K. Bayazit, "A comparison of the early and midterm results after dynamic cardiomyoplasty in patients with ischemic or idiopathic cardiomyopathy.," The Journal of thoracic and cardiovascular surgery, vol. 113, no. 1. pp. 173-80; discussion 180-1, Jan-1997.

[133] O. Tasdemir, K. M. Vural, S. D. Kucukaksu, O. K. Tarcan, M. Ozdemir, E. Kutuk, and K. Bayazit, "Comparative study on cardiomyoplasty patients with the cardiomyostimulator on versus off," Ann.Thorac.Surg., vol. 62, no. 0003-4975 (Print), pp. 17081713, Dec. 1996.

[134] R. K. Thakur, L. H. Chow, G. M. Guiraudon, W. J. Kostuk, J. E. Brown, P. V. Pflugfelder, and C. M. Guiraudon, "Latissimus dorsi dynamic cardiomyoplasty: role of combined ICD implantation.," Journal of cardiac surgery, vol. 10, no. 4 Pt 1, pp. 295-7, Jul. 1995.

[135] J. Timmerman, J. M. Van Der Maaten, J. M. Wierda, a a Broekema, H. E. Mungroop, M. H. Brouwer, and M. P. Van Den Berg, "The use of neuromuscular blocking agents in noncardiac surgery after dynamic cardiomyoplasty.," Anaesthesia, vol. 54, no. 9, pp. 879-82, Sep. 1999.

[136] J. Trainini, J. C. Barisani, E. I. Cabrera Fischer, S. Chada, A. I. Christen, and B. Elencwajg, "Chronic aortic counterpulsation with latissimus dorsi in heart failure: clinical follow-up," J.Heart Lung Transplant., vol. 18, no. 1053-2498 (Print), pp. 1120-1125, Nov. 1999.

[137] J. Trainini, E. I. Cabrera Fischer, J. Barisani, A. I. Christen, J. Mouras, P. J. de, B. Elencwajg, and J. C. Chachques, "Dynamic aortomyoplasty in treating end-stage heart failure," J.Heart Lung Transplant., vol. 21, no. 1053-2498 (Print), pp. 1068-1073, Oct. 2002.

[138] J. C. Trainini, "Dynamic Cardiomyoplasty and Aortomyoplasty: the Buenos Aires Experience," Basic Appl.Myol., vol. 8, no. 6, pp. 413-18, 1998.

[139] L. Tritapepe, P. Voci, G. D'Amati, A. Cogliati, A. Menichetti, and P. Gallo, "Neuromuscular relaxants in non-cardiac surgery after cardiomyoplasty.," Canadian journal of anaesthesia = Journal canadien d'anesthésie, vol. 45, no. 4, pp. 324-7, Apr. 1998.

[140] M. P. van Den Berg, D. Nagelkerke, R. M. Brouwer, H. Mulder, H. de Boer, and H. J. Crijns, "Feasibility of pacemaker therapy after dynamic cardiomyoplasty.," Pacing and clinical electrophysiology: PACE, vol. 22, no. 10, pp. 1543-6, Oct. 1999.

[141] B. Voss and R. Lange, "[Dynamic cardiomyoplasty: evaluation of an alternative procedure in the treatment of terminal heart failure].," Zeitschrift für Kardiologie, vol. 90 Suppl 1, no. 0300-5860 (Print), pp. 22-7, Jan. 2001. 
[142] K. M. Vural, O. Tasdemir, S. D. Küçükaksu, O. K. Tarcan, and K. Bayazit, “Optimization of synchronization delay in latissimus dorsi dynamic cardiomyoplasty.," The Annals of thoracic surgery, vol. 65, no. 5, pp. 1231-4, May 1998.

[143] C. Werling, C. Jungheim, and W. Saggau, "Dynamic Cardiomyoplasty: Clinical Experience after Seven Years," Basic Appl.Myol., vol. 10, no. 3, pp. 113-117, 2000.

[144] M. B. Yilmaz, O. Tufekcioglu, S. Korkmaz, and I. Sabah, “Dynamic cardiomyoplasty: impact of effective pacing.," International journal of cardiology, vol. 91, no. 1, pp. 101-2, Sep. 2003.

[145] J. B. Young and K. J. K, “Cardiomyoplasty-Skeletal Muscle Assist Randomized Trial (C-SMART): 6 Month Results," in Circulation (Suppl.), 1999.

[146] P. Poole-Wilson, K. Swedberg, J. Cleland, A. Di Lenarda, P. Hanrath, M. Komajda, J. Lubsen, B. Lutiger, M. Metra, W. Remme, C. Torp-Pedersen, A. Scherhag, A. Skene, and for the C. Investigators*, "Comparison of carvedilol and metoprolol on clinical outcomes in patients with chronic heart failure in the Carvedilol Or Metoprolol European Trial (COMET): randomised controlled trial," Lancet, vol. 362, pp. 7-13, 2003.

[147] E. Rose, A. Gelijns, A. Moskowitz, D. Heitjan, L. Stevenson, W. Dembitsky, J. Long, D. Ascheim, A. Tierney, R. Levitan, J. Watson, P. Meier, N. Ronan, P. Shapiro, R. Lazar, L. Miller, L. Gupta, O. Frazier, P. Desvigne-Nickens, M. Oz, and V. Poirier, "Randomized Evaluation of Mechanical Assistance for the Treatment of Congestive Heart Failure (REMATCH) Study Group Long-Term Use of a Left Ventricular Assist Device for End-Stage Heart Failure," N Engl J Med, vol. 345, no. 20, pp. 1435-1443, 2001.

[148] J. G. F. Cleland, J.-C. Daubert, E. Erdmann, N. Freemantle, D. Gras, L. Kappenberger, L. Tavazzi, and for the C. R. - H. F. (CARE-H. S. Investigators*, "The Effect of Cardiac Resynchronization on Morbidity and Mortality in Heart Failure," N Engl J Med, vol. 352, pp. 1539-49, 2005.

[149] I. S. of H. and L. ISHLT (Transplantation, "Heart Transplantation-Annual Report 2011," J Heart Lung Transplant., vol. 30, no. 10, pp. 1071-1132, 2011.

[150] S. J. Park, C. A. Milano, A. J. Tatooles, J. G. Rogers, R. M. Adamson, D. E. Steidley, G. A. Ewald, and D. J. F. and M. S. Slaughter, Kartik S. Sundareswaran, “Outcomes in Advanced Heart Failure Patients with Left Ventricular Assist Devices for Destination Therapy," Circulation Heart Fail, vol. 5, no. 2, pp. 241-8, 2012.

[151] P. Strauer Donndorf, G. Kundt, A. Kaminski, C. Yerebakan, A. Liesbold, G. Steinhoff, and A. Glass, "Intramyocardial bone marrow stem cell transplantation during coronary artery bypass surgery: a meta-analysis," J Thorac Cardiovasc Surg, vol. 142, no. 4, pp. 911-20, 2011.

[152] B. Strauer and G. Steinhoff, "10 Years of Intracoronary and Intramyocardial Bone marrow Stem Cell Therapy of the Heart," JACC, vol. 58, no. 11, pp. 1095-104, 2001. 
[153] P. Donndorf, G. Kundt, A. Kaminski, C. Yerebakan, A. Liebold, G. Steinhoff, and A. Glass, "Intramyocardial bone marrow stem cell transplantation during coronary artery bypass surgery: a meta-analysis," J Thorac Cardiovasc Surg, vol. 142, no. 4, pp. 911-20, 2011.

[154] N. Guldner, Kajahn, M. Klinger, H. Sievers, and C. Kruse, “Autonomously contracting human cardiomyocytes generated from adult pancreatic stem cells and enhanced in co-cultures with myocardial biopsies," Int J Artif Organs, vol. 29, pp. 1158-66, 2006.

[155] N. W. Guldner, P. Klapproth, P. O. Schwarz, T. Hardel, P. Rumpf, J. Kajahn, P. Margaritoff, H. H. Sievers, and M. Grossherr, “Bio-technologies for a glandular stem cell cardiomyopexy," Ann Anat, vol. 191, no. 1, pp. 45-50, 2009.

[156] Mathieu-Costello and E. Al., "Capillary-to-fibre surface ratio in rat fast-twitch hindlimb muscles after chronic electrical stimulation," J Appl Physiol, vol. 80, no. 3, pp. 904-909, 1996.

[157] J. Dawson and O. Hudlicka, "The effect of long-term activity on the microvasculature of rat glycolytic muscle," Int J Microcirc, vol. 8, pp. 53-69, 1989.

[158] A. Lopez-Guajardo, H. Sutherland, J. Jarvis, and S. Salmons, "Induction of a fatigueresistant phenotype in rabbit fast muscle by small daily amounts of stimulation," $J$ Appl Physiol, vol. 90, no. 5, pp. 1909-18, 2001.

[159] N. Guldner, H. Eichstaedt, P. Klapproth, and E. Al., "A method to increase muscular power for cardiac assistance," Circulation, vol. 89, pp. 1032-1040, 1994.

[160] N. Guldner, P. Klapproth, M. Grossherr, and et al., “Clenbuterol-supported dynamic training of skeletal muscle ventricles against systemic load: a key for powerful circulatory assist?," Circulation, vol. 101, pp. 2213-2219, 2000.

[161] N. Guldner, P. Klapproth, M. Grossherr, and E. Al., "Biomechanical hearts: muscular blood pumps, performed in a 1-step operation, and trained under support of clenbuterol," Circulation, vol. 104, pp. 717-722, 2001. 